\section{Seguro Garantia em Infraestrutura no Brasil: Perspectivas de Custos de Transação e Teoria da Agência}

\author{
Surety Bond in Infrastructure in Brazil: Transaction Costs and Agency Theory \\ Perspectives
}

\author{
Tulio Henrique Moreira Marques*1 10 \\ Mario Henrique Ogasavara ${ }^{2}$ (อ \\ Frederico Araujo Turolla ${ }^{2}$
}

\section{RESUMO}

Contexto: projetos de infraestrutura pressupóem o uso de capital intensivo e a participaçáo de diversos atores, onde o ambiente institucional influencia seus respectivos arranjos contratuais. Um instrumento financeiro para a governança é a utilização do seguro garantia (SG) cuja finalidade é garantir o cumprimento do objeto contratado. Entretanto, ainda são incipientes pesquisas que envolvam o uso do SG no contexto de países emergentes como o Brasil. Objetivo: com o objetivo de compreender o uso do SG no Brasil e propor um modelo conceitual de análise das transaçôes, este artigo contribui para a literatura ao investigar a relação entre os atores e transaçóes envolvidos no SG utilizando as perspectivas da teoria de custos de transaçáo da teoria da agência. Métodos: adotou-se metodologia qualitativa com dados primários provenientes de 10 entrevistas em profundidade semiestruturadas junto a profissionais do mercado com notória experiência em SG, e como dados secundários, debate e palestra específicas sobre o tema envolvendo a realidade e o uso do SG. Resultados: os resultados indicam que os problemas de agência e os elevados custos de transação presentes no Brasil impedem o desenvolvimento desse mercado de cobertura de riscos, ensejando políticas públicas direcionadas. Conclusáo: o modelo conceitual proposto traduz as várias transaçôes específicas no uso do $\mathrm{SG}$, os fenômenos subjacentes e a comprovação de proposiçóes relacionadas às falhas de mercado e à influência do ambiente institucional.

Palavras-chave: seguro garantia; projetos de infraestrutura; Brasil; teoria de custos de transação; teoria da agência.

\footnotetext{
* Autor Correspondente.

1. Escola Superior de Propaganda e Marketing, Programa de Pós-graduação em Administração, São Paulo, SP, Brasil.

2. Escola Superior de Propaganda e Marketing, Programa de Doutorado e Mestrado em Gestão Internacional, São Paulo, SP, Brasil.

Como citar: Marques, T. H. M., Ogasavara, M. H., \& Turolla, F. A. (2022). Seguro garantia em infraestrutura no Brasil: Perspectivas de custos de transação e teoria da agência. Revista de Administração Contemporânea, 26(3), e200401. https://doi.org/10.1590/1982-7849rac2022200401.por

Publicado em Early Access: 18 de Novembro, 2021.

Designado a essa edição: 10 de Dezembro, 2021
}

\# de revisores convidados até a decisão:

\begin{tabular}{llll} 
\# de revisores convidados até a decisão: & \\
\hline $1^{a}$ rodada & \\
$2^{a}$ rodada &
\end{tabular}

\section{ABSTRACT}

Context: infrastructure projects assume the use of intensive capital and the participation of several actors, where the institutional environment influences their respective contractual arrangements. A financial instrument for project governance is surety bond (SB), whose purpose is to ensure compliance with the contracted object. However, research involving SB in the context of emerging countries such as Brazil is still incipient. Objective: this study aims to understand the use of SB in Brazil and proposes a conceptual model for analyzing transactions. It contributes to the literature by investigating the relationship between the actors and transactions involved in SB using the transaction costs theory and agency theory perspectives. Methods: this study adopts a qualitative methodology using primary data collected with 10 indepth semi-structured interviews with market professionals with substantial experience in SB. In addition, it uses secondary data based on debate and a specific lecture on the topic involving the reality and the use of SB. Results: the findings indicate that the agency problem and the high transaction costs in Brazil prevent the development of this risk coverage market, giving rise to targeted public policies. Conclusion: the proposed conceptual model reflects the various specific transactions in the use of SB, the underlying phenomena and the validation of propositions related to market failures, and the institutional environment's influence.

Keywords: surety bond; infrastructure projects; Brazil; transaction costs theory; agency theory.

Classificaçāo JEL: G22, L14

Editores-chefes: Wesley Mendes-da-Silva (Fundação Getulio Vargas, EAESP, Brasil) (1) Marcelo de Souza Bispo (Universidade Federal da Paraíba, PPGA, Brasil)
Editores Convidados: João Vinícius de França Carvalho (Universidade de São Paulo, FEA, Brasil) Eduardo Flores (Universidade de São Paulo, FEA, Brasil) (1) Emiliano A. Valdez (University of Connecticut, EUA) (c) Pareceristas: Luis Eduardo Afonso (Universidade de São Paulo. FEA, Brasill Guilherme Fowler de Ávila Monteiro (INSPER Instituto de Ensino e Pesquisa, Brasil) Relatório de Revisão por Pares: O Relatório de Revisão por Pares está disponivel neste link externo. Recebido: $30 / 11 / 2020$ Última versão recebida em: 03/08/2021 Aceite em: 06/08/202 


\section{INTRODUÇÃO}

Seguro garantia (SG) é um tipo de seguro que subscreve o adimplemento das obrigaçóes assumidas pelo contratado junto ao contratante, com base nas condiçóes da apólice emitida. Em um ambiente de incertezas cada vez maiores, a exigência e a busca por instrumentos que garantam o cumprimento dos acordos, como, por exemplo, em grandes projetos de infraestrutura, têm sido cada vez maiores. Segundo o The Insight Partners (2020), o mercado global de SG deve crescer de USD 16,07 bilhóes em 2019 para USD 25,18 bilhóes até 2027, impulsionado pela demanda por restauração da infraestrutura antiga dos países desenvolvidos. O mercado de SG no Brasil contou com 35 empresas em operação e movimentou até setembro de 2020 o valor de $\mathrm{R} \$ 2,3$ bilhóes. Isso representa um aumento relativo em comparação ao ano completo de 2019, em que registrou o montante de $\mathrm{R} \$ 2,16$ bilhóes $(2,4 \%$ do mercado mundial) gerados por 280 mil apólices de grandes obras, contratos e ações judiciais (Superintendência de Seguros Privados [Susep], 2020a). É um mercado que terá uma maior expansão particularmente com o sancionamento presidencial da nova Lei de Licitaçóes n. ${ }^{\circ}$ 14.133 de 01/04/2021 (Lei n. 14.133, 2021). Há uma previsão de aumento do valor das garantias para obras e serviços de grande vulto de $10 \%$ para $30 \%$, o que trará um incremento significativo no volume de prêmios recolhidos, tornando esse mercado mais pujante nos próximos anos (Superintendência de Seguros Privados [Susep], 2020b).

Quando se olha para estudos acadêmicos, a literatura em SG vem abordando o tema dentro de uma perspectiva de risco (Beg, 2019; Kim, Cho, \& Ryu, 2019; Surahyo, 2018; Wambach \& Engel, 2011), contexto jurídico (Efing \& Desiderio, 2019; Maia, 2013) ou à luz de uma realidade distinta desses mercados. No Brasil, autores como Poletto (2003) e Buranello (2006) aanalisaram a natureza jurídica do SG; Poveda (2012) apresentou o SG como instrumento de gestão para mitigação de danos ambientais na mineração; Somavilla e Pereira (2018) estudaram a utilização da performance bond nos contratos administrativos de obras públicas à luz da lei n.o 8.666/93; Terra e Salgado (2020) analisaram os efeitos produzidos pelo inadimplemento anterior ao termo nos contratos de SG.

Todavia, ainda há uma incompreensão sobre a utilizaçáo do SG no Brasil em uma perspectiva da relaçáo dos atores envolvidos considerando os aspectos estruturais e institucionais nas transaçóes em projetos de infraestrutura. Isto porque, diferente de um seguro tradicional em que a relaçáo é bilateral e se consolida entre o segurado e a seguradora, o SG envolve algumas especificidades como uma relação tripartite entre segurado, tomador e seguradora, o que torna a relação ainda mais complexa. Além disso, em projetos de infraestrutura há uma alta especificidade de ativos, os quais exigem inúmeros requisitos e informaçóes com um prazo curto para tomada de decisão. Isso pode favorecer a assimetria informacional entre as partes, o oportunismo e o aumento da incerteza. Com isso, este estudo buscará entender essas relaçóes utilizando as perspectivas da teoria de custos de transaçáo (TCT) e da teoria da agência (TA) para avaliar os custos ex-ante e ex-post envolvidos na transação específica via SG.

Assim, o presente artigo pretende contribuir para a literatura de SG em três principais pontos. Primeiro, compreendendo melhor os mecanismos que estabelecem as relaçóes contratuais existentes em projeto de infraestrutura onde houve a utilização do SG. Segundo, identificando as incompletudes de mercado no tocante à eficácia do SG, as quais incorrem em problemas de agência, elevam os custos de transação e eventualmente produzem barreiras à sua utilização em projetos de infraestrutura. Finalmente, propondo um modelo conceitual das relaçóes e transaçóes existentes no SG no mercado brasileiro, que poderá auxiliar na melhor gestão e uso dessa ferramenta em projetos de infraestrutura.

Esta pesquisa utilizou abordagem qualitativa, por meio de análise de conteúdo de dados primários coletados em entrevistas em profundidade com profissionais de grande expertise em SG, e dados secundários baseados em debate e palestra específicos sobre o tema. Os resultados mostraram que os problemas de agência e os altos custos de transaçáa no Brasil impedem uma maior expansão do mercado de SG, implicando a necessidade de elaboração de políticas públicas específicas.

$\mathrm{O}$ artigo encontra-se estruturado da seguinte forma: após a introdução, a segunda seção apresenta o contexto sobre o SG. Na sequência, é apresentada a revisão da literatura de TCT e TA, bem como as respectivas proposiçóes do estudo. $\mathrm{Na}$ quarta seção, os procedimentos metodológicos são detalhados, seguida da seção de análise e discussão dos resultados. A sexta seção apresenta as consideraçôes finais, as contribuiçóes e implicaçóes, bem como as limitaçóes e direçôes para futuras pesquisas na área.

\section{CONTEXTO - O SEGURO GARANTIA (SG)}

O Insurance Act de 1601 define o seguro a partir de três objetivos: (a) distribuir as perdas de alguns entre muitos; (b) encorajar aqueles que são reticentes para assumir riscos antes da garantia de uma compensação; e (c) convocar os mais jovens a serem empreendedores (Akinradewo, Aghimien, Aigbavboa, \& Onyia, 2020). Pode-se perceber o importante instrumento de incentivo ex-ante para redução dos custos de transaçáo cujos termos ecoam mesmo atualmente (Tzirulnik, 2015), sendo apontado por diversos 
autores o caráter positivo e relevante do mercado de seguro na dinâmica econômica e social (Hansell, 1996; Pradhan, Arvin, Nair, \& Bennett, 2020).

As seguradoras são como investidores institucionais menos dispostos a se opor às administraçóes das sociedades (Coffee, 1991) e as cláusulas do seguro são uma forma de reduzir os custos de agência (Smith \& Warner, 1979). Seguradoras reúnem e administram as contribuiçóes destinadas a garantir as unidades econômicas expostas ao surgimento de necessidades, ao homogeneizar os riscos na comunidade, coletivizando os custos oriundos de sinistros cobertos, sendo que a operação securitária é um fenômeno coletivo e indissociável (Tzirulnik, 2015). O seguro é universalmente requerido para reduzir os custos relacionados à contratação, controle e conflitos (Krummaker, 2016).

Com relação ao SG, o propósito é garantir ao segurado a prestação de execução substituta ou pagamento pelos prejuízos que aquele venha a sofrer em consequência do inadimplemento contratual do tomador, devedor da obrigação no contrato garantido (Beg, 2019; Terra \& Salgado, 2020). Enquanto os seguros de danos visam a repor o bem no estado em que se encontrava antes do sinistro, no SG o objetivo é mais amplo: satisfazer o cumprimento da obrigação assumida pelo tomador por meio do contrato principal (Kim, et al., 2019; Surahyo, 2018), ou seja, uma falha de mercado na estrutura de contratação tem consequências também mais amplas.

O conceito fundamental subjacente no SG é que a inadimplência do contratante tomador é evitável e não um caso fortuito (Schubert, 2000). O SG pode ser uma solução racional e eficaz para assimetrias de informação presentes nas transaçóes comerciais, a qual é complexa e especificamente adaptada aos problemas existentes nessas relaçóes (Mann, 1998).

Esse é um tipo de seguro com características peculiares, pois apesar de apresentar os elementos formais típicos do mercado de seguros (apólice, sinistro e prêmio), o risco é analisado no contexto do próprio projeto e com grande ênfase no tomador do seguro em ambiente de financiamento do respectivo projeto (Brockett, Golden, \& Betak, 2019). Enquanto o SG se refere a um mecanismo de 'loss avoidance', desenhado para pré-qualificar indivíduos baseado em suas capacidades de crédito e expertise construtiva, o seguro tradicional é um mecanismo de 'loss funding', desenhado para compensar o segurado contra eventos imprevistos adversos (Russel, 2000).

Enquanto em seguros convencionais há um cálculo atuarial estatístico baseado no comportamento geral da carteira de segurados (Hoffmann \& Girolamo, 2017), o SG tende a ter um comportamento mais parecido com um seguro de crédito (Russel, 2000). O prêmio não é calculado com base na possibilidade de ocorrência de um evento, mas sim com base em um crédito financeiro da garantia ao principal, onde o processo de subscrição é mais rigoroso, em que o tomador deve fornecer todas as informaçóes confidenciais sobre suas finanças e planos de negócios (Beg, 2019). Galiza (2015) pondera se o SG pode ser considerado um seguro propriamente dito, uma vez que há algumas características desse produto que não coadunam com o padrão usualmente estabelecido em um seguro tradicional. A Tabela 1 compara os elementos típicos do SG e do seguro tradicional.

Tabela 1. Comparativo entre as características do SG e do seguro tradicional.

\begin{tabular}{|c|c|}
\hline Seguro garantia & Seguro tradicional \\
\hline Transação tripartite & Transação bilateral \\
\hline Não se espera a ocorrência de sinistro & O sinistro é esperado \\
\hline Cobre obrigações contratuais do tomador junto ao segurado & Cobre eventos determinados, ou todos os riscos (all risks) exceto aqueles excluídos \\
\hline Por princípio, as três partes se beneficiam da relação & O benefício principal é a pulverização de eventuais perdas \\
\hline O prêmio é pago pelo tomador & O prêmio é pago pelo segurado \\
\hline $\begin{array}{l}\text { Por princípio, o prêmio não se destina a cobrir pagamentos de sinistros, } \\
\text { mas sim custos de investigaçáo/monitoramento técnico e financeiro, custos } \\
\text { administrativos e de comissão }\end{array}$ & $\begin{array}{l}\text { O prêmio se destina a cobrir eventuais pagamentos de sinistros, custos } \\
\text { administrativos e de comissáo }\end{array}$ \\
\hline $\begin{array}{l}\text { A vigência está associada à duração de um projeto específico e, geralmente, } \\
\text { as apólices são renovadas anualmente }\end{array}$ & $\begin{array}{l}\text { A vigência da apólice tem um período específico - em geral, um ano } \\
\text { (exceção, por exemplo, para os riscos de engenharia) }\end{array}$ \\
\hline A vigência da apólice perdura mesmo sem o pagamento do prêmio & $\begin{array}{l}\text { A vigência é reduzida, cancelada ou suspensa em caso de náo pagamento do } \\
\text { prêmio }\end{array}$ \\
\hline Seguradora pode exigir garantias financeiras & Seguradora não exige garantias financeiras \\
\hline Ausência do princípio de mutualismo & Há o princípio do mutualismo \\
\hline Direito de regresso sobre o tomador, em caso de pagamento de indenização & $\begin{array}{l}\text { Não há a figura do tomador; o eventual regresso é sobre o terceiro causador } \\
\text { do sinistro }\end{array}$ \\
\hline
\end{tabular}

Nota. Baseada em Russell (2000); Poletto (2003); Buranello (2006); Galiza (2015); Hoffmann e Girolamo (2017) e Brockett, Golden e Betak (2019). 
Mann (1998) esclarece que o uso de terceiras partes altera de maneira importante a dinâmica da transação, pois: (a) estabelece vínculo mediante a responsabilidade legal, sem remover ativos do uso produtivo; (b) cria a oportunidade de uma segunda verificaçáo quanto à credibilidade do tomador; $\mathrm{e}$ (c) provê a confiabilidade da garantia esperada pelo segurado, mediante a própria reputação da seguradora. As relaçôes jurídicas que se formam dentro do SG são múltiplas, com características específicas e cujos efeitos decorrentes do inadimplemento dos contratos merecem tratamento próprio (Efing \& Desiderio, 2019).

Nesse contexto, Haddad e Amaral (2011) estabelecem a relação jurídica do $S G$ e as respectivas diferenças em relação à fiança bancária. Esses autores indicam que, em vista do risco de inadimplemento de obrigação a cargo do tomador no âmbito do contrato principal, o próprio tomador contrata a apólice de SG para cobertura de tal risco junto à seguradora. Em contrapartida, o tomador assina um contrato de contragarantia (indenminity agreement) no qual se compromete a reembolsar a seguradora em caso de qualquer pagamento que esta vier a efetuar em favor do segurado (Poveda, 2012). Por sua vez, a seguradora se obriga ao pagamento da indenização ao segurado (obligee) na hipótese de sinistro, segundo os termos da apólice e pelas normas emanadas do órgão regulador (Haddad \& Amaral, 2011). Nesse aspecto, os elementos balizadores do contrato de SG são "bastante peculiares em comparação com as outras espécies de contratos de seguro" (Maia, 2013, p. 31).

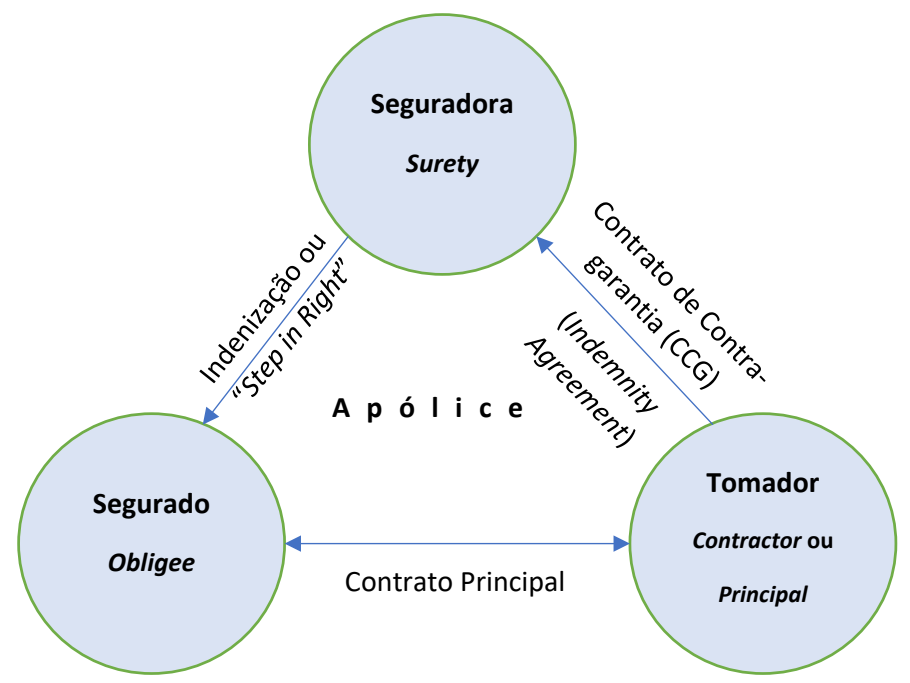

Figura 1. Relação jurídica criada pelo seguro garantia. Fonte: Elaborado pelos autores a partir de Haddad e Amaral (2011).

No Brasil, é importante destacar que a seguradora, em caso de sinistro e dependendo das condiçóes contratuais, pode optar por indenizar o segurado pelo prejuízo decorrente do inadimplemento por parte do tomador até o limite da verba contratada ou exercer o direito de finalizar o objeto da apólice (step-in right). Tal dispositivo é inexistente em outras modalidades de seguro, pois a seguradora intervém no contrato no sentido de resolver inadimplementos e regularizar as atividades do empreendimento, preservando as garantias e contratos do projeto (Monteiro, 2016).

\section{REVISÃO DA LITERATURA}

\section{Teoria dos custos de transação (TCT)}

As relaçóes de mercado e o papel regulador das instituiçôes estabelecem as diretrizes básicas para o estudo e o desenvolvimento da TCT (Coase, 1937). Os pressupostos comportamentais da racionalidade limitada e do oportunismo são balizadores das estruturas de contrato e de governança, sendo a incerteza, a especificidade dos ativos e a frequência os atributos mais relevantes para descrever as transaçóes (Williamson, 2012). Os custos de transação nascem da necessidade de estabelecer o cumprimento dos acordos, onde a informação não é apenas dispendiosa, mas também incompleta, e a execução não é apenas cara, mas também imperfeita (North, 1992). A essência central da TCT é a minimização dos custos de transação, tendo na seleção dos mecanismos de governança o seu grande reduto, a qual é detalhada segundo a frequência e a especificidade de ativo presentes em cada tipo de transação, dado que a incerteza é esperada e preexistente (Williamson, 2012). Publicaçôes mais recentes exploram a especificidade de ativos e a relevância da incerteza nas estruturas de governança (Schnaider, Ménard, \& Saes, 2018). Existem duas dimensóes de incerteza: (a) decorrente da própria transação que se origina de vazios institucionais e aumenta os custos de transação; e (b) 
incerteza econômica que surge do ambiente de negócios (Smit, Pennings, \& Van Bekkum, 2017). Os efeitos de uma e de outra não são necessariamente os mesmos. Enquanto na primeira a inexistência de mecanismos eficazes pode ser corrigida por meio de algum dispositivo regulatório, a segunda obedece a um contexto macroeconômico setorial, cuja análise deve ser realizada dentro de conjetura mais ampla.

A regulação exerce um papel importante não apenas em presença de monopólio natural, mas é uma resposta aos problemas criados pelo jogo espontâneo dos mercados em matéria de produção de bens ou fornecimento de serviços (Dumez \& Jeunemaitre, 2000), pressupondo certo equilíbrio entre os interesses das diversas forças sociais envolvidas (Gentot, 1991). Segundo Williamson (2012) "se o modo proposto é imperfeito em contextos similares ou diferentes, as pretensas vantagens de abandonar a regulação podem ser ilusórias" (Williamson, 2012, p. 299). Não há intervenção governamental, nem mesmo regulaçáo, sem uma tentativa das coalizóes de manipular seu resultado onde a burocracia segue seu caminho e pode ser considerada o nexo entre influências conflitantes (Estache \& Martimort, 1999).

Os contratos são incompletos, onerosos, e esses custos influenciam a escolha de contingências explicitamente contempladas (Hart \& Moore, 2007), sendo o oportunismo um dos responsáveis por essa condiçāo (Williamson, 2012). Estudos anteriores abordam as relaçóes de confiança entre parceiros comerciais (Baker, 2016; Chiles \& Mcmackin, 1996), existindo dimensóes separadas para sua obtenção: competência e integridade, sendo esta última mais potente para reduzir os custos de transação (Connelly, Crook, Combs, Ketchen, \& Aguinis, 2018). Enquanto a competência opera dentro da racionalidade limitada, a integridade significa reduçâo do oportunismo.

A preferência pela transação via contrato cresce em relação ao mercado quando há convicção no amparo do sistema legal, pressupondo: (a) propensão em antecipar como a outra parte irá se comportar dentro de um contexto de racionalidade limitada, incentivos oportunistas e desejo pela mitigação de riscos (Chiles \& Mcmackin, 1996); (b) a transferência de responsabilidades de fornecimento para outra parte, mediante determinação de preços, incentivos, controles e penalidades (Bhimani, Lopes, \& Aquino, 2016); (c) baixas confiança e interdependência (Yao, Zhang, \& Brett, 2017).

Williamson (2012) define (a) custos ex-ante como aqueles incorridos na negociação e formatação de acordos; (b) custos ex-post como aqueles que envolvem configuração e funcionamento da estrutura de governança, incluídos os custos de falta de adaptação, vinculação e disputa - sendo que os dois sáo interdependentes e devem ser analisados de forma simultânea. A incerteza influencia tanto os custos ex-ante como os ex-post (Williamson, 2012), seja pela possível escolha errada do parceiro, seja por falha no desenho contratual (Marques \& Berg, 2011).

Falhas de mercado têm origem nos custos de transação, podendo até impedir a formação de mercados. $\mathrm{O}$ chamado paradigma Arrow-Debreu constitui um referencial na literatura de mercado completo, onde todos os riscos são cobertos em um mercado líquido e eficiente (Arrow, 1964).

Quando o mercado não consegue por conta própria alocar recursos de forma eficiente do ponto de vista social (ex.: sem uma regulamentaçáo do Estado), fica caracterizada a falha de mercado. Em grandes projetos de infraestrutura, há uma assimetria informacional que faz com que o governo interessado, ao contratar o empreendimento com um parceiro privado (contratado, licitante, concessionário, pepepista, sociedade de propósito específico), não consiga identificar a priori, na licitação de contrataçáo, o tipo desse parceiro ou as informaçóes por este mantidas ocultas, como a sua capacidade de execução e/ou sua real intenção de completar o empreendimento.

Quanto mais complexo, único e idiossincrático o produto, mais complexos são o contrato e as decisōes que envolvem o capital e as estruturas de governança. Produtos que envolvem grandes riscos e incertezas contratuais podem levar a comportamentos oportunistas, gerando com isso conflitos entre as partes interessadas e aumento nos custos de transação (Dionne, 2013).

\section{Teoria da agência (TA) e TCT}

A teoria de agência (TA) é tida como uma das mais antigas na literatura de gestão/economia. Ela discute os conflitos de interesse na relação contratual entre principal ${ }^{1}$ e agente, sendo este último revestido de poderes para administrar o negócio em nome daquele, proprietário ou acionista da empresa. Trata-se de uma teoria multidisciplinar que pode ser usada em outros campos do conhecimento envolvendo as relaçóes sociais e interorganizacionais (Panda \& Leepsa, 2017). Os custos de agência nascem devido à (a) separaçáo entre propriedade e controle, (b) diferentes preferências de risco, (c) assimetria de informação e (d) riscos morais. Jensen e Meckling (1976) estabelecem que os custos de agência sáo representados pela soma dos custos de elaboração e formalizaçáo dos contratos, os custos de fiscalizaçáo do agente, do título e aqueles associados à perda residual (Navarro Sanfelix \& Puig, 2018).

Kim e Mahoney (2005) estabelecem uma comparação entre TA e TCT em alguns aspectos por meio de uma matriz. Por um lado, eles indicam que a unidade de análise é o contrato entre o principal e o agente na TA, enquanto na TCT, é a transação. Além disso, eles mostram que a dimensão principal são os incentivos na TA e tipos de especificidade de ativos na TCT. Mas, por outro lado, ambas as teorias compartilham a mesma intenção estratégica (visão do acionista), além de alguns pontos em comum entre eles em termos de fontes de atrito de 
mercado, como assimetria de informação. No entanto, o foco contratual é totalmente diferente: na TA, é o alinhamento de incentivos ex-ante, e na TCT, a escolha de mecanismos de governança ex-post.

Segundo Williamson (2002), a complementaridade entre as abordagens da TA e da TCT está associada a questóes de governança: enquanto a primeira concentra o estudo nos fenômenos ex-ante à contratação, a última tem um foco maior nos aspectos ex-post à concretização da troca (Silva, 2006). A TA complementa a TCT em razão de aquela explicar a resolução de conflitos entre partes interessadas (Dionne, 2013).

Baranoff e Sager (2002), em estudo sobre a indústria do seguro de vida, indicam que as duas teorias preveem que conflitos maiores, gerados pelas partes interessadas ou por produtos mais arriscados, levam à reduçáo da alavancagem ou aumento do capital para mitigar as incertezas devido aos atritos. Sun, Garimella, Han, Chang e Shaw (2020) analisam um provedor de plataforma descentralizada de seguros, baseada em blockchain, via utilização dessas duas lentes teóricas. Esse estudo conclui, entre outras coisas, que a introdução do blockchain traz (a) dois benefícios à relação peer-to-peer: transparência e confiança, (b) além de redução dos custos de transação ex-ante e de agência.

\section{Aplicação ao seguro garantia}

\section{Atributos da transação}

O conjunto de transaçóes sob análise é realizado entre atores de mercados distintos em uma relação tripartite (segurado-tomador-seguradora), havendo diversas transaçóes periféricas que a suportam em um contexto de elevada assimetria informacional, baixa frequência (custos de transação menores) e uma alta especificidade de ativos (ver Tabela 2).

Tabela 2. Qualificação dos atributos presentes no conjunto de transaçóes do seguro garantia no mercado de infraestrutura, segundo sua intensidade no contexto.

\begin{tabular}{lll}
\hline Atributo & Intensidade & Justificativa \\
\hline Incerteza & Elevada & Assimetria informacional \\
Frequência & Baixa, mas com estrutura de governança especializada & Número de interaçóes seguradora-tomador \\
Especificidade de ativo & Elevada & Relação de longo prazo entre as partes \\
\hline
\end{tabular}

Nota. Elaborada pelos autores.

A incerteza é elevada, dentre outros motivos, porque o segurado náo consegue determinar, a priori, o tipo de tomador. No SG, a relação tem ainda complicadores adicionais. Não se trata apenas de uma relação seguradosegurador como em um ambiente mutual de outros produtos típicos da indústria de seguros. Por isso, a configuração da transaçáo aumenta a incerteza presente no processo. O papel da seguradora nesse tipo de transação é de reduzir a incerteza, mas naturalmente estará sujeita a uma incerteza típica dessa relação, já que nos serviços financeiros, o fornecedor tem em regra menos condiçôes de avaliar a probabilidade de uma perda futura (Zweifel \& Eisen, 2012).

Sobre a frequência, trata-se de uma ocorrência bastante pontual (anualmente) ligada a projetos de características únicas e eventuais, com amplo período de planejamento, estruturação e execução que invariavelmente consome anos ou décadas com uma estrutura de governança especializada.

Sobre a especificidade de ativos, o prêmio pago no SG não serve como um fundo para perdas futuras (loss funding), mas sim como um loss avoidance. Isso implica que a seguradora tome parte ativa no processo de prevençáo da ocorrência de sinistro e na mitigaçáo dos efeitos de sua materialização, com realização de monitoramento regular quanto à completude do projeto em casos específicos, e cláusulas típicas como step-in right. Nesse sentido, a seguradora engaja-se em um relacionamento próximo com tomador e segurado, no qual deve haver grande volume de troca de informaçóes específicas à transação. Portanto, a transação apresenta todos os requisitos para a situação de elevados custos de transação, com as consequências típicas apontadas na literatura, como a transformação fundamental (Williamson, 2012) e creeping expropriation (Graham, Johnston, \& Kingsley, 2018).

É importante destacar que tanto a frequência como a especificidade de ativo nas transações são idênticas no que tange à infraestrutura, independentemente do tipo de mercado. A diferença entre um mercado desenvolvido e um emergente se concentra na incerteza menor ou maior que pode ser oriunda de alguns fatores, conforme detalhado no tópico seguinte.

\section{Modelo conceitual da transação do SG}

Em princípio, uma assimetria informacional dá causa aos riscos contratuais em projetos complexos de infraestrutura. Trata-se de uma falha de mercado que, doravante, será identificada como assimetria informacional primária (AIP), que frequentemente vem associada a um problema de agência. A AIP, em um mercado completo no modelo Arrow-Debreu, seria mitigada por instrumentos 
como o SG, que eliminariam a AIP e permitiriam a contratação eficiente.

Com base na literatura, propõe-se um modelo conceitual (Figura 2) que identifica a incidência da AIP e da manifestaçáo de assimetrias de informaçáo secundárias (AIS, $\mathrm{AIS}_{2}, \mathrm{eAIS}_{3}$ ) na forma de seleçáo adversa, além do oportunismo contratual no mercado brasileiro. $\mathrm{Na}$ literatura de seguro tradicional, outras questóes, notadamente a seleção adversa e o risco moral ${ }^{2}$ são identificadas como oportunismo ex-ante $\mathrm{e}$ ex-post (Williamson, 2012). Estas podem ser originadas tanto pelo segurado como pela seguradora, gerando externalidades negativas como os custos derivados da perda de confiança no instrumento do seguro (Baker \& Logue, 2017). No caso em tela, se verifica a manifestação da AIP e de um problema de agência primário (PAP), enquanto secundariamente aparecem o oportunismo e a seleção adversa.

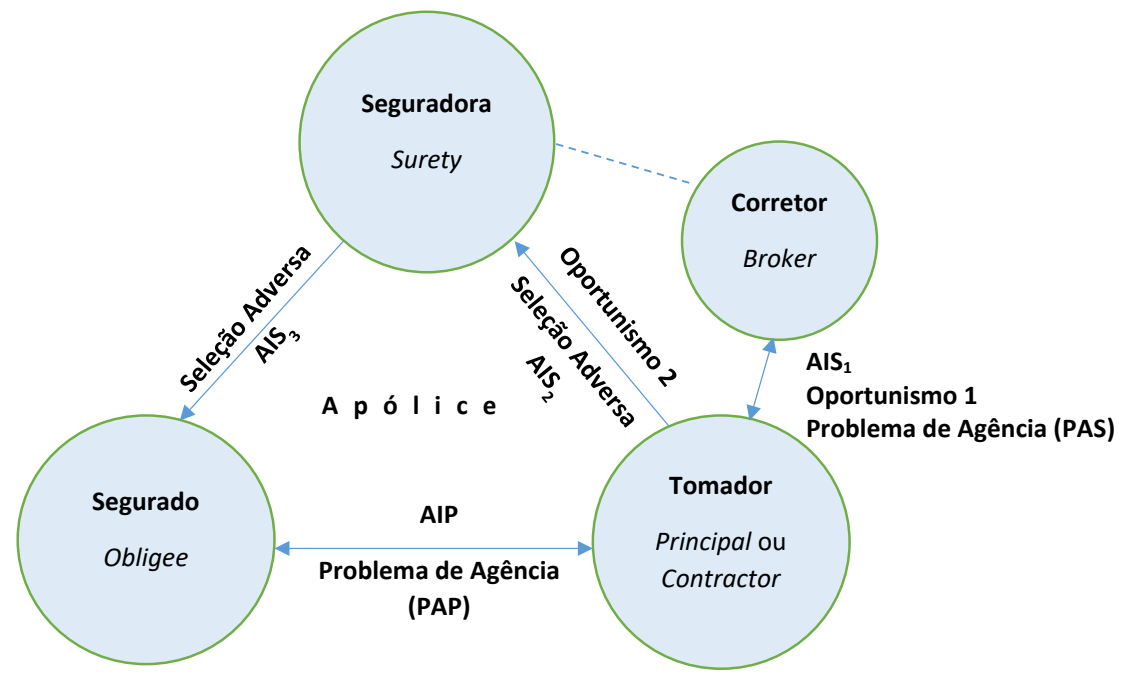

Figura 2. Modelo teórico da transação do SG no Brasil. Fonte: Elaboração própria.

No SG, esses fenômenos acarretam renegociaçóes dos termos contratuais, aumentos de custos e tempo de conclusão, e perda de eficiência dos contratos públicos (de infraestrutura), os quais são transferidos e arcados por todos os contribuintes (Giuffrida \& Rovigatti, 2019). A mitigação desses comportamentos oportunistas pode acontecer em funçáo de regras institucionais (North, 1992). Ou seja, regras institucionais adequadas podem mitigar os comportamentos oportunistas que comprometem a efetividade do SG contra a AIP entre tomador e segurado, tornando a sua aplicação mais direcionada ao paradigma Arrow-Debreu.

Em que pese o fato de as garantias serem uma resposta a problemas potenciais de risco moral e de seleção adversa (Giuffrida \& Rovigatti, 2019), quando as instituições não oferecem o adequado suporte contra os comportamentos oportunistas, os custos de transação são elevados. Em outras palavras, em mercados onde as garantias de finalização de projeto náo são efetivas, o SG deixa de ter o efeito esperado de gerar um mercado mais completo, desviando-se do paradigma Arrow-Debreu. Ceteris paribus o oportunismo contratual, o SG é um mitigador da AIP entre o tomador e o segurado. Quando se insere o oportunismo no ambiente contratual, essa mitigação da AIP pelo SG fica reduzida ou comprometida, levando à seguinte proposição:

P1: A mitigação da AIP através do SG é comprometida pelo oportunismo contratual em mercados emergentes como o Brasil.

O conjunto de transaçóes no mercado de SG enfrenta uma dissociação entre quem decide pela contratação do seguro (segurado) e quem escolhe a seguradora e paga o valor do prêmio (tomador). A percepçáo de risco por parte do tomador, no caso do SG, tende a ser subestimada, o que se reflete no preço do seguro (prêmio) e na amplitude de cobertura contratada (Giuffrida \& Rovigatti, 2019). Nessa condiçáo, o tomador náo tem incentivos para internalizar as externalidades infligidas à administração por sua escolha (Engel, Ganuza, Hauk, \& Wambach, 2006). Assim, a AI ex-ante no mercado de SG tende a incentivar a contratação, pelo tomador, de seguradoras de menor qualidade e/ou seguros que, na prática, podem náo trazer a cobertura de riscos desejada pelo segurado (Giuffrida \& Rovigatti, 2019). Em um sentido mais amplo, pode ser considerado um problema de agência (Jensen \& Meckling, 1976). 
A relação entre segurado e tomador no âmbito do SG implica o estabelecimento de algum nível de confiança sobre o instrumento que o tomador, como agente, contratará em nome do segurado, estabelecendo-se uma relaçáo de agência. Confiança no produto/serviço é a crença de que este cumprirá suas funçóes conforme entendido pelo comprador. O perfeito conhecimento do produto/serviço é fortemente associado à confiança do comprador (Newell, Wu, Leingpibul, \& Jiang, 2016). Ribeiro, Machado e Tinoco (2010) identificaram a confirmação das expectativas e a qualidade percebida como determinantes da satisfação da qualidade em serviços bancários.

Porém, diferente do serviço bancário, o mercado de seguros náo oferece ao consumidor o uso imediato de seus serviços, tratando-se apenas de uma promessa de cumprimento da obrigação no momento da emissão da apólice, caso haja materialização do risco coberto no futuro. Em outras palavras, é uma obrigação cuja realização é contingente a um estado da natureza ou a uma ação/ informação oculta. Nesse aspecto, a percepção e a satisfação da qualidade estão forte e positivamente relacionadas entre si, sendo que os determinantes para percepção positiva do serviço prestado são a assertividade, a acessibilidade, a imagem corporativa, a honestidade, a competência e a confiança (Lakshimi \& Santhi, 2015). A confirmação das expectativas e a observação efetiva da qualidade do serviço prestado só ocorrem, no sistema de SG, quando há uma frequência razoável de sinistros em que é acionada a cláusula de step-in. Embora em mercados emergentes o número de sinistros possa ser significativo (Guasch, Laffont, \& Straub, 2008), a experiência mostra que poucos casos chegam ao uso do step-in, não gerando esses requisitos. Assim, propóe-se:

P2a: O problema de agência primário (PAP) do SG é potencializado quando segurado e tomador não confirmam a expectativa da finalização do projeto, nem percebem a qualidade do serviço prestado pela seguradora.

Um elemento que pode interferir na AI no SG é a participação do corretor de seguros que, em um ambiente de decisão altamente técnica, assume um papel informacional privilegiado em sua posiçáo de assessor (advisor). Esse agente, que está autorizado a elaborar e aprovar previamente o cadastro do tomador, a negociar em nome deste condiçóes de taxa e de cobertura, cujo beneficiário final é o segurado (Pereira, 2017) pode fazer uso de forma oportunista do conjunto de informaçóes de que dispóe em detrimento dos interesses do segurado (ex.: reduzindo o preço do seguro através de uma cobertura limitada e/ou direcionando à cotação para uma seguradora que paga uma comissão maior) sem contudo atender plenamente às exigências requeridas nesse tipo de arranjo (Hau, 2011; Outreville, 2012). Essa condição pode levar também a um problema de agência secundário (PAS), quando o corretor age em seu interesse próprio, sem atender às expectativas do tomador que o nomeou (Figura 2). Caso o corretor seja competente, a AIS tende a diminuir. Caso o corretor seja ético, as chances de haver oportunismo e/ou PAS são reduzidas. Entretanto, estruturas de governança relacional são mais adequadas a ativos baseados em conhecimento (knowledge-based assets), como em SG, devido à inabilidade de especificar de forma antecipada e precisa processos e resultado (Hoetker \& Mellewigt, 2009), levando à seguinte proposição:

P2b: O problema de agência primário (PAP) no SG pode ser mitigado via adequaçóes de mercado e estruturas de governança.

A dificuldade de existirem sistemas legais e judiciais dotados de imparcialidade que garantam o cumprimento de acordos pode ser considerada uma falha de mercado (North, 1992), assim como a inexistência de uma jurisprudência consolidada, homogênea e presumível (Pinheiro, 2014). Tais questóes comprometem o desenvolvimento econômico através de custos de transaçáo elevados expressos pela insegurança jurídica, a qual afeta não somente os credores, que podem utilizar de procedimentos desleais e oportunistas, mas também os tomadores, seja pela reduzida oferta de crédito, seja pela prática de altos spreads bancários (Yeung, Silva, \& Carvalho, 2014).

\section{Riscos em grandes projetos de infraestrutura}

O principal problema em grandes projetos de infraestrutura são informaçóes erradas sobre benefícios (superestimados), bem como custos e riscos (subestimados), o que acarreta não só aumento dos custos de transaçãa, mas também o surgimento de externalidades como redução de benefícios e desperdício (Flyvbjerg, Garbuio, \& Lovallo 2009). Estruturas de governança reduzem riscos e favorecem a eficiência de análise e viabilidade de projetos a um custo ínfimo (Williamson, 2012), mediante a participação de outras organizaçóes interessadas (ex.: bancos e seguradoras). Essas organizaçóes realizam espécies de due diligence (exante) que produzem efeitos no cumprimento das obrigaçóes (ex-post), reduzindo a AI por serem eficientes na seleção e monitoramento de riscos (Azevedo, Silva, \& May, 2018).

\section{Insegurança jurídica e SG}

As instituições regulatórias e judiciais constituem elementos centrais da proteçáo de contratos (Marques \& Turolla, 2017), sendo que as últimas vêm ganhando cada vez mais protagonismo dentro da sociedade (Marciano, Melcarne, \& Ramello, 2019). Altos custos de transação causam distorções nos mercados, como o subincentivo 
ex-ante à oferta de instrumentos de mitigação de riscos que, em última instância, dependem do sistema judicial para sua exigibilidade, como o exemplo no mercado brasileiro de SG apontado por Hoffmann e Girolamo (2017).

Falhas no sistema judiciário podem comprometer a efetividade do direto corporativo em mercados emergentes, seja pela falta de robustez das garantias exigidas pelas seguradoras, como o contrato de contragarantia (CCG), seja pelo grande lapso temporal de uma ação judicial (Black \& Kraakman, 1996), a qual pode ser utilizada de forma oportunista por tomadores que usam a justiça como meio de administrar suas dívidas. Portanto:

P3: A insegurança jurídica em mercados emergentes como o Brasil impede o exercício do direito da seguradora de finalizar o objeto da apólice no SG.

Seguros e garantias funcionam para alinhar os incentivos subjacentes de forma a produzir um resultado conjuntamente favorável para ambos os parceiros, público e privado. Contudo, nem sempre esse alinhamento de incentivos ocorre de maneira razoável (Marques \& Turolla, 2017). Isso porque os altos custos de transaçáo impedem a obtenção de um contrato com incentivos poderosos no sentido desejado. Essa é a importância dos custos de transaçáo, os quais impedem que se desenvolvam os sistemas de incentivo contratual adequados aos projetos de infraestrutura, e que em última instância impedem o desenvolvimento de projetos de infraestrutura de alto valor econômico e social.

O exagero do poder punitivo e sua forma burocrática dentro do setor público podem caracterizar o direito administrativo do medo (DAM), gerando ineficiências ao funcionamento da máquina estatal (Campana, 2017; Gondim, Rosário, \& Freire, 2018; Guimarães, 2016). O desenvolvimento de uma categoria relacionada a "características da política" (ex.: simplicidade, idade da política, precisão da política, abordagem política, envolvimento e participação do público, além de credibilidade e consistência da política) foi proposto por Shahab, Clinch, e O'Neill (2018) para destacar a importância da escolha e do respectivo desenho de um instrumento de política de planejamento em termos de custos de transação. Com isso, propóe-se:

P4: Burocracia e insegurança dos agentes reguladores em mercados emergentes como o Brasil são barreiras ao exercício do step-in right em projetos de infraestrutura.

Giuffrida e Rovigatti (2019) encontraram evidências de que o SG no mercado americano ajuda a manter a taxa de inadimplência baixa, aprimorando a seleção dos melhores contratados. Assim, exigências legais de aumento dos percentuais garantidos podem elevar o comprometimento das seguradoras com os projetos segurados (Guasch, 2004). O efeito é de gerar uma maior escala, que tende a aumentar a solidez das seguradoras, ainda que sob os riscos da maior concentraçáo desse mercado e da maior AI, com repasse mais intensivo dos grandes riscos aos resseguradores.

Fatores externos ou internos oriundos (ou não) de limitaçôes institucionais (Estache, Serebrisky, \& WrenLewis, 2015) como sistema legal ineficiente ou a própria estrutura deficiente de contrato reduzem a propensão dos tomadores em honrar seus compromissos, aumentando também a percepção de risco por parte das instituiçôes financeiras envolvidas e, consequentemente, os custos de transação. Portanto:

P5a: Na ausência de exigência legal sobre mínimos de garantias, em mercados emergentes como o Brasil, previsões baixas reduzem o comprometimento das seguradoras.

P5b: Percentuais elevados de garantia geram maior commitment das seguradoras mediante subscrição mais detalhada do risco (ex ante) e monitoramento adequado ao longo do contrato (ex post).

\section{METODOLOGIA}

A presente pesquisa é de abordagem qualitativa baseada em entrevistas em profundidade, semiestruturadas, com perguntas predefinidas de acordo com a literatura utilizada. Por meio de um processo dedutivo-indutivo (Guest, Namey, $\&$ Mitchell, 2013), participaram da pesquisa 10 profissionais que possuíam pelo menos 10 anos de experiência no SG nos mercados do Brasil (mercado emergente) e nos EUA (mercado maduro). A escolha desses países decorre do fato de inexistir no Brasil casos bem-sucedidos de step-in right no setor público, em contraste com a realidade americana, onde o $\mathrm{SG}$ é amplamente utilizado pelos governos, com diversos casos exitosos. Três entrevistas foram realizadas no período agostosetembro/2017 e as outras sete em agosto-setembro/20193. Sete profissionais atuam no mercado brasileiro e foram entrevistados pessoalmente em seus escritórios e três, que atuam nos EUA, foram entrevistados por telefone. O tempo de duraçáo de cada entrevista variou entre $30 \mathrm{~min}$ e $1 \mathrm{~h} 10 \mathrm{~min}$, tendo gerado mais de 12 horas de gravação. Foi realizada a análise do conteúdo, com o suporte do software NVivo.11 visando o maior rigor, transparência e organização (Maher, Hadfield, Hutchings, \& Eyto, 2018). Durante a condução da pesquisa foram realizadas triangulaçóes, mediante matriz de amarração, envolvendo os seguintes tópicos: (a) revisão da literatura; (b) proposição; (c) categorias de análise; (d) entrevistas (trechos); (e) dados secundários; (f) identificação dos respectivos momentos da transação, e quais categorias 
de análise se verificam. Para um entendimento acerca das características dos entrevistados, apresentamos a Tabela 3 a seguir.

Além disso, foram utilizados dados secundários obtidos em uma palestra realizada por meio de videoconferência em 2016 (1h37min) e um debate realizado em 2019 (1h45min), ambos em São Paulo, com a participação de diversos profissionais envolvidos no tema, que abordam em profundidade o SG respectivamente em relaçáo ao mercado americano e brasileiro (Tabela 4).

Tabela 3. Características dos executivos entrevistados.

\begin{tabular}{clcccc}
\hline Ident. & \multicolumn{1}{c}{ Posição } & $\Delta \mathrm{t} / \mathrm{n}$. $^{\circ}$ páginas & Profissão & Atuação & Experiência \\
\hline E1 & Ex-executivo de seguradora & $0: 37: 00 / 11$ & Engenheiro & Brasil & 23 anos \\
E2 & Executivo de seguradora & $0: 40: 00 / 15$ & Advogado & EUA & 24 anos \\
E3 & Sócio de escritório de advocacia & $0: 45: 00 / 23$ & Advogado & Brasil & 21 anos \\
E4 & Sócio de escritório de advocacia & $0: 54: 43 / 30$ & Advogado & Brasil & 20 anos \\
E5 & Sócia de escritório de advocacia & $0: 45: 26 / 13$ & Advogada & Brasil & 24 anos \\
E6 & Ex-executivo de seguradora & $1: 15: 00 / 20$ & Advogado & EUA & 40 anos \\
E7 & Executiva de seguradora & $0: 49: 24 / 27$ & Advogada & Brasil & 17 anos \\
E8 & Sócia de escritório de advocacia & $1: 02: 00 / 30$ & Advogada & Brasil & 10 anos \\
E9 & Executivo de seguradora & $1: 11: 00 / 24$ & Administrador & EUA & 18 anos \\
E10 & Executivo de corretora & $1: 14: 00 / 24$ & Advogado & Brasil & 36 anos \\
\hline
\end{tabular}

Nota. Elaboração própria.

Tabela 4. Características dos dados secundários.

\begin{tabular}{cccccc}
\hline Ident. & Posição & $\Delta \mathrm{t} / \mathrm{n} .^{\mathrm{o}}$ páginas & Profissão & Atuação & Experiência \\
\hline $\mathrm{P}$ & Executivo de resseguradora & $1: 37: 12 / 25$ & Especialista & EUA & 20 anos \\
$\mathrm{D}$ & Diversas & $1: 58: 00 / 38$ & Diversas & Brasil & N/A \\
\hline
\end{tabular}

Nota. Elaboração própria.

A partir desse material (mais de 280 páginas de transcriçãa) foi possível a identificação de diferenças entre essas duas jurisdiçóes em termos de capacidade do instrumento SG de funcionar como mitigador de risco em projetos de infraestrutura. As entrevistas seguiram estrutura baseada nos elementos identificados na teoria, incluindo questóes obtidas de forma indutiva (Figura 2).

\section{ANÁLISE E DISCUSSÃO DOS RESULTADOS}

Com base nos dados obtidos nas entrevistas/dados secundários, a análise foi subdividida em três grupos: (a) aspectos estruturais; (b) aspectos da transação; e (c) aspectos institucionais.

\section{Aspectos estruturais (confiança)}

Os aspectos estruturais consistem em questóes que o mercado ou seus atores podem endereçar no intuito de difundir o SG, de tornar o seu uso mais habitual, de capacitar profissionais que nele atuam e, ainda, de compatibilizar os clausulados existentes tanto da apólice como também do contrato principal/edital. Mostra a importância de o beneficiário, principalmente o poder concedente, conhecer o produto. Destacam-se a seguir os principais temas identificados nas entrevistas/dados secundários.

\section{Difusão e conhecimento do produto, despreparo profissional, adequação/ compatibilidade de clausulados}

Ainda existe uma incompreensão sobre as regras que norteiam o SG, principalmente dentro do poder concedente. Essa realidade permite inferir, com base na literatura (Comer, Plank, Reid, \& Pullins, 1999), que dentro do mercado emergente, como o Brasil, há uma baixa confiança no instrumento do $S G$ em razão do próprio desconhecimento sobre os mecanismos que balizam o seu uso. Essa situação não se verifica apenas do lado do segurado/beneficiário, mas no mercado como um todo, o que engloba corretores e seguradoras. A realidade norte-americana é distinta, conforme quase todos os entrevistados confirmam, tratando-se de um mercado bastante especializado. 
O desconhecimento do produto no mercado brasileiro causa distorçóes e incompatibilidades difíceis de serem contornadas, como, por exemplo, entre editais e apólices. Tal fenômeno, não incomum, faz com que o produto seja ineficaz, tornando o ambiente propício para o oportunismo de todos os atores. Adicionalmente, a falta de alocaçáo de risco adequada em vários modelos de editais agrava a situação, mas, mesmo assim, as seguradoras aceitam emitir apólice nessas condiçóes, o que caracteriza um oportunismo.

As distorçôes são tantas que se trata de um instrumento para o qual não existe registro da utilizaçáo do dispositivo de step-in dentro do setor público no Brasil, não cumprindo dessa forma a função estratégica que dele se espera. A eficácia do SG está diretamente relacionada à conectividade dele com o contrato principal, uma vez que não se trata de um produto autônomo.

É evidente que o contrato (e o edital que o originou) é apenas uma parte dessa questáo. A estruturação de um projeto de infraestrutura engloba equipes multidisciplinares e envolve, entre outros aspectos, premissas técnicas de engenharia, aspectos jurídicos e legais, bem como estudos econômicofinanceiros aprofundados. Todo esse trabalho precisa apontar uma matriz de riscos com a respectiva alocaçáo (ao ente privado e/ou público) mais capaz de absorvê-los, e as formas de eliminálos, mitigá-los ou transferi-los.

A difusão do SG no mercado americano tem impacto positivo no nível de especialização dos profissionais que nele atuam, alcançando a confiança por meio da competência (Connelly et al., 2018). A situaçáo inversa, no Brasil, de pouca difusão/especialização e, principalmente, da não confirmação da função social (step-in) do SG dentro do setor público, faz com que em parte exista também uma grande desconfiança no mercado, o que corrobora Ribeiro et al. (2010) e Lakshimi e Santhi (2015).

\section{Aspectos da transação}

Os aspectos da transação estão associados às relações que se estabelecem dentro do mercado e às respectivas falhas como a seleção adversa, problemas de agência, e o risco moral. Outro elemento que de certa forma é transversal a todos os anteriores e reflete o momento (ex-post) em que tais fenômenos podem ser melhor identificados é o da expectativa de sinistro.

\section{Assimetria de informação ex ante: seleção adversa}

As relaçóes no mercado de SG brasileiro apresentam idiossincrasias favoráveis à existência de externalidades negativas com altos custos de transação envolvidos. Verificase uma situação de competitividade de mercado, em que os ofertantes do instrumento competem em preço. Porém, os projetos de infraestrutura pressupóem elevada especificidade de ativo, exigindo o mesmo por parte daqueles que têm o papel de analisar e precificar o risco.

A própria postura do tomador espelha a dinâmica da licitaçáo, quando o assunto envolve a capacidade daquele em finalizar o projeto. A mentalidade do empreendedor é de ter plena certeza de que vai ser tudo resolvido. Essa rapidez e superficialidade na análise é fruto do oportunismo corroborado por Williamson (2012). Em contraposiçáo, o mercado americano se caracteriza por relaçóes longevas de 20-30 anos entre tomadores e seguradoras.

Embora haja diferenças entre os dois mercados, é interessante observar que existem muitas práticas comuns, como o fato de os pedidos de cotaçáo serem feitos com muito pouco tempo de antecedência para sua efetiva apreciação por parte da seguradora. O relacionamento entre tomador e segurado de longa data nos EUA permite aprovaçóes de limites instantâneas. Isso decorre do profundo conhecimento e confiança que a seguradora possui sobre o tomador (cliente de longa data).

\section{Problema de agência}

A contratação do SG no Brasil é norteada pela busca do menor preço, pois o tomador, aquele que paga o prêmio, não enxerga o instrumento como elemento importante nas situaçóes contratuais em que se pode lançar mão da garantia. Na verdade, o beneficiário é o segurado e, aos olhos do tomador, apenas lhe resta o ônus de arcar com os custos de algo que ele não tem incentivo para adquirir, exceto a exigência contratual. Soma-se a isso a falta de interesse por parte do ente público durante o processo de contratação. Ou seja, o tomador tem uma espécie de mandato para escolher o SG que for do seu interesse, sem levar em consideração as necessidades do beneficiário.

Por outro lado, segundo o Debatedor D, as seguradoras "entram nessa competição comercial comandadas muitas vezes pelo próprio tomador, o corretor é uma vítima porque ele acaba sendo pressionado pelo tomador para correr atrás da menor taxa. E quando chega na menor taxa, ele fala: 'péra um pouco: as cláusulas do contrato ..., eu não gosto. Muda aqui essas cláusulas para ficar mais fácil para mim’. Então ele vai na menor taxa e nas condiçóes mais favoráveis". Já o Entrevistado E8 questiona quem o corretor representa (o segurado, a seguradora, ou ele mesmo): “... tem alguma negociaçáo de comissão que ele também tem um certo interesse. Então até que ponto existe a imparcialidade de oferecer todos aqueles produtos ou ... valor?"

Outro aspecto importante é o fato de o poder concedente tentar "transformar a garantia de performance numa garantia financeira que não cumpre o objetivo do seguro", cobrindo "multa moratória [diária]. ... O Estado faz caixa com seguro" (Entrevistado E4). As externalidades positivas geradas pela 
completude dos projetos de infraestrutura vão muito além do que o mero pagamento de multas, cujo destino geralmente é alheio ao projeto em si.

$\mathrm{O}$ conflito de interesse existente entre tomador e segurado é aceito por quase todos os envolvidos, pois ele não chega a desnaturar ou prejudicar o instrumento. A AI no SG no Brasil se dá de duas formas distintas: (a) pelo desconhecimento do produto; e (b) pela seleção adversa que está associada ao risco (tomador), e é fruto do problema de agência em potencial que o produto originalmente apresenta. De toda forma, o problema de agência nasce da baixa identificabilidade na escolha do licitante vencedor (associada à AIP) e cresce na seleção adversa secundária $\left(\mathrm{AIS}_{1}, \mathrm{AIS}_{2}\right.$ ) quando a simbiose tomador-seguradora é marcada pelo elevado oportunismo das partes envolvidas. É importante notar que a figura do corretor nesse processo é relevante, pois caso este profissional reúna as dimensóes de competência e integridade, discutidas na literatura, haverá uma tendência ao alinhamento entre o melhor risco e o melhor instrumento mitigador desse risco.

Ou seja, a seleçâo adversa advém da relação seguradoratomador que, como observado nas entrevistas/dados secundários, não é tão adversa assim, uma vez que ela é marcada pelo oportunismo desses dois atores. Já a seleçâo adversa da seguradora $\left(\mathrm{AIS}_{3}\right)$, oriunda da relação tomador-segurado, ocorre quando a garantia oferecida náo atende plenamente aos interesses do beneficiário, tendo este ator dificuldade em observar tal situação de forma antecipada. Há uma conexão entre a seleção adversa e o problema de agência, até porque existe um elo em comum: o tomador. Mas o risco que o tomador oferece à seguradora não é necessariamente igual ao risco que a seguradora oferece ao segurado. $O$ problema de agência é anterior à seleção adversa pelo próprio timing do negócio, tendo em vista os processos de licitação e contratação, típicos dos contratos de concessão ou de infraestrutura (Yescombe \& Farquharson, 2018).

Quando analisamos a dinâmica das mesmas relaçóes no mercado americano, nota-se a influência não só das instituiçôes formais, mas sobretudo das informais. Embora não seja o foco deste artigo abordar os aspectos socioculturais, não se pode ignorar o poder que estes exercem nos arranjos institucionais.

O direito de step-in, quando exercido de forma eficaz, é o coroamento das boas escolhas e poderia ser o cartáo de visita das seguradoras de surety bond no Brasil junto ao setor público. Infelizmente, o mercado segurador nacional ainda não possui essa evidência, e a percepçáo, tanto daquele que paga a garantia (tomador) quanto do beneficiário (segurado), é de que o SG não oferece aquilo que ele promete. Isso faz com que ambos os atores tentem maximizar os seus resultados, seja pagando o menor preço (e o pior serviço), seja se aproveitando de mecanismos existentes no próprio produto que compensem ou justifiquem a existência do instrumento, levando à aceitação da P2a. Em relação à P2b, ela foi parcialmente comprovada no que se refere a adequaçóes de mercado. A segunda parte dessa proposição relativa a estruturas de governança não foi evidenciada, restando o aprofundamento da questáo em pesquisas futuras.

\section{Assimetria de informação ex post: moral hazard}

A literatura de seguros versa sobre o risco moral por parte do segurado (Reis, 2012), mas no SG esse risco pode vir do tomador também. Enquanto no seguro tradicional a mudança de comportamento do segurado nem sempre é percebida ao longo da vigência da apólice, no SG a seguradora pode fiscalizar a execuçáo do contrato. Esse dispositivo contratual pode fazer toda a diferença na relaçáo firmada segurado-tomadorseguradora, diminuindo as chances da concretização de um sinistro ou diminuindo as perdas caso ele de fato ocorra.

No entanto, o monitoramento dos contratos não é feito em sua plenitude. $\mathrm{Na}$ verdade, isso é um problema tanto no mercado americano como no brasileiro. Porém, há maior transparência nos EUA. O tomador no Brasil muitas vezes prefere omitir a informação por medo de agravamento no prêmio. O monitoramento tem o condáo de antever problemas, mas a razão para sua ausência é o respectivo custo. Essa realidade é observada nos dois mercados, mas no Brasil isso é agravado pela própria competição das taxas (se o prêmio é baixo, não há espaço para um monitoramento efetivo).

Os inadimplementos contratuais são intrínsecos ao monitoramento que, no Brasil, vêm em grande medida do próprio governo. A participação mais ativa dentro da relação contratual por parte das seguradoras acarreta custos de transação e, devido ao oportunismo e à baixa remuneração, elas preferem correr o risco de não realizar o monitoramento.

Essa situação tende a mudar, conforme mencionado acima, em decorrência da Lei $n^{\circ}$ 14.133/2021 em que está previsto que "a seguradora deverá firmar o contrato, inclusive os aditivos, como interveniente anuente" (Lei n. 14.133, 2021).

O mercado americano talvez possa se dar ao luxo de não realizar o monitoramento da forma correta, uma vez que ele tem a seu favor uma baixa $\mathrm{AI}$ aliada à solidez das relaçôes entre tomadores e sureties. No entanto, o risco moral presente no mercado de SG brasileiro pode estar associado a todos os atores, inclusive a seguradora, pois ela não realiza o serviço que poderia prover. Como isso é facultado à seguradora, as companhias em geral optam por não fazer o monitoramento, mesmo em um ambiente de alta AI e baixa confiança.

Ainda que isso decorra da estratégia perseguida por cada seguradora, os dados das entrevistas revelam que esse fenômeno se dá de maneira antecipada, no momento da aceitação do risco, caracterizando assim uma seleção adversa da seguradora, ou uma seleção adversa "às avessas". Entretanto, não se pode afirmar que se trata de uma seleção adversa aleatória, haja vista 
que o tomador busca obter a garantia que oferece o menor custo, cujo pressuposto pode ser o pior serviço e/ou a cobertura mais restritiva. Não se pode generalizar essa situação, mas é um dos achados da pesquisa. Dessa forma, para que essa garantia sirva como mitigador dos riscos desejados pelo beneficiário da forma com que a literatura apresenta (Giuffrida \& Rovigatti, 2019), é fundamental que haja redução da $\mathrm{AIS}_{3}$, mediante dispositivos contratuais dentro da licitação.

\section{Regulação de sinistro}

Em que pese o fato de um processo de regulação e liquidação de sinistro garantia ser complexo, nos EUA ele é muito fluido, não podendo exceder mais do que 30 dias. Entretanto, a dinâmica da relação entre as partes dentro da legislação americana faz com que a sinistralidade seja de no máximo $20 \%$.

A seguradora possui seis opçóes para liquidar o sinistro "predefinidas já nos clausulados” (Debatedor D): “(1) ela pode assumir e completar o projeto, o famoso assumir e completar; "(2) licitar um novo contratado"; "(3) financiar o contratado original para completar o projeto; "(4) indenizar o segurado"; "(5) transferir ... a obrigaçáo da garantia”; e "(6) negar o sinistro". Sendo que as formas mais usuais de conclusão de projeto são: "ou ... a seguradora de alguma forma assume [a obra] ... ou terceiriza ou traz alguém de fora”. Mas um dado que faz toda a diferença no mercado americano é que "não é uma opção da seguradora pagar [indenização]" como no Brasil.

O tempo e a burocracia existentes em muitos processos de sinistro de garantia no mercado brasileiro, principalmente aqueles envolvendo órgáos públicos, parecem ser os elementos que mais destoam. Isso reflete um pouco do próprio direito brasileiro e, de novo, a realidade das instituiçóes informais.

Há ainda, no Brasil, um agravante em relação à autonomia do poder concedente, no sentido de "viabilizar acordos na esfera administrativa, embora já exista mediaçáo, arbitragem" (Entrevistado E5). No entanto, esses dispositivos de resolução de conflitos ainda precisam ser assimilados pelo Estado. Nos EUA, o problema não é o tempo: "a arbitragem é mais incerta do que a justiça” porque, em geral "o SG tem uma forte posição legal" e "os árbitros não precisam seguir o que os tribunais têm definido como regra" (Entrevistado E6).

Muitos problemas poderiam ser resolvidos rapidamente se não fosse a inexistência de subscrição ou os contratos teratológicos que não dialogam entre si. Outros, pela própria especificidade dos projetos, podem tornar a realização do step-in algo extremamente complexo de ocorrer, demandando por sua vez uma sofisticação dos profissionais que atuam na regulação de sinistros. Essa, por sua vez, é a etapa mais crítica dentro de qualquer seguro. Nesse processo, é comum o surgimento de vários temas para discussão - questôes não observadas no tempo devido, problemas mal resolvidos, aspectos que extrapolam as letras do contrato, entrada de novos atores (não envolvidos na relaçáo original), desencontro de informaçóes, enfim, muitas variáveis e pouquíssimas equaçóes para solução. Soma-se a isso o animus de litigância entre as partes, numa relação que, não raro, já vem desgastada por motivos diversos.

A complexidade dos projetos e contratos abrangidos no SG pode ser elevada, principalmente no caso de infraestrutura, independentemente do país. O mercado de SG americano apresenta uma qualidade na prestaçáo de serviço de tal ordem que o permite: (a) resolver rapidamente os sinistros mesmo que sem um monitoramento adequado; (b) oferecer um leque maior de opçóes predefinidas para liquidação, em que o beneficiário é soberano quanto à escolha final. Contudo, o poder público nos EUA possui mais autonomia e comprometimento na resolução de sinistros, além de uma maior compreensão sobre o SG.

Em resumo: (a) no Brasil, a resolução de conflitos pode durar anos (quando náo mais de década, por meio da judicialização); (b) o Estado por muito tempo foi e ainda continua sendo na sua maior parte inoperante, burocratizado, o que dá margem ao oportunismo das seguradoras e também dos tomadores; (c) o arcabouço legal não incentiva a celeridade dos processos; (d) o DAM está sempre presente nos órgáos públicos; (e) o Estado ainda não está preparado para a resolução de conflitos pela via da mediaçáo ou da arbitragem, ou seja, a judicialização é a regra; (f) de maneira geral, o poder concedente desconhece o instrumento do SG.

Embora muitas das seguradoras brasileiras que operam com SG sejam multinacionais (com expertise no mercado americano), elas ainda apresentam um nível de prestação de serviço muito aquém do das norte-americanas, sem a incorporaçáo das melhores práticas do ramo. Isso ocorre tanto na aceitação e precificação do risco como no monitoramento e sinistro. A Lei n. 14.133 (2021), que será mais discutido no próximo tópico, traz alguns avanços que exigirão das seguradoras um protagonismo que hoje poucas conseguiriam ter. Por isso, elas podem vir a adotar procedimentos que compensem a 'gravidade' do beneficiário público, onde tudo emperra, tudo demora. Uma das opçóes para tanto (dentro dos limites das seguradoras) pode ser o monitoramento efetivo dos projetos (pelo menos daqueles mais complexos) para a solução ser mais imediata no caso de um sinistro.

À luz da teoria, a fluidez dos processos por meio do conhecimento das regras entre todos os atores, do arcabouço legal que privilegia os contratos (common law), da agilidade nos procedimentos, da proatividade e autonomia dos gestores públicos, e da desburocratização dos serviços administrativos, reduz os custos de transaçáo. Contudo, a realidade brasileira torna os custos de transação bem mais elevados, especialmente na presença do oportunismo.

O trabalho dos tribunais de contas poderia contribuir para uma maior consistência em todo o processo. No entanto, 
eles acabam instaurando o DAM, causando efeito inverso (Campana, 2017; Gondim et al., 2018). Esse fenômeno faz com que, em casos críticos, o gestor público opte por transferir seu poder de decisão ao judiciário. $\mathrm{Na}$ verdade, o judiciário brasileiro tem sido um escudo de proteção tanto para o poder executivo (segurado/beneficiário) quanto para o devedor (tomador) - o primeiro se exime de expor seu CPF por atos considerados 'errados' pelos tribunais de contas, e o outro administra suas dívidas, rolando-as no tempo da ineficiência da justiça e dos recursos previstos em lei.

O step-in é o objetivo almejado por toda sociedade. E o único caminho viável para isso, dentro dos limites do setor privado, é a prestaçấo de serviço de qualidade: regulaçấo de sinistro bem-sucedida com transparência e fluidez nas informaçóes. De nada adianta haver reguladores e peritos qualificados se o problema estiver na origem da contratação. Grande parte da solução se concentra na segurança jurídica, que será abordada na sequência. Mas a mediação e a auditoria externa feitas com isenção, precedidas por um monitoramento adequado dos projetos, são as formas de governança que permitirão às seguradoras alcançar um nível reputacional no SG equiparável a outras empresas em diferentes ramos do mercado segurador. Assim, dá-se suporte à proposição P4.

\section{Aspectos institucionais}

Os aspectos institucionais fazem menção à legislação, à regulação e à insegurança jurídica que interferem diretamente nos aspectos da transaçáo e indiretamente nos aspectos estruturais.

\section{Legislação}

A literatura apresenta indícios de que os percentuais de cobertura estão positivamente relacionados ao comprometimento das seguradoras e, portanto, à efetividade do SG (Guasch, 2004; Giuffrida \& Rovigatti, 2019). No Brasil, a Lei n. 14.133 (2021), ao propor a elevaçáo do percentual de cobertura para $30 \%$, apresenta alguns aspectos que merecem uma análise mais detalhada. Um aspecto contraintuitivo dessa proposta é o aumento do volume agregado dos custos de transação associado aos próprios contratos de SG. Dessa forma, a proposição $\mathrm{P} 5$ endereça um tema atual do mercado segurador brasileiro ao lidar com a questão da exigência legal de elevação do percentual de cobertura.

Há uma unanimidade no mercado de que os percentuais previstos no ordenamento atual (5\%-10\%) são insuficientes para a finalização de qualquer projeto, conforme todos os profissionais que participaram da pesquisa. Isso significa que a performance bond só consegue atender às multas aplicadas pela administração pública. Entretanto, nos EUA, as garantias começam em $100 \%$, o que torna mais factível a completude dos projetos.

Outra razão para o step-in ainda não ser factível no Brasil, principalmente no setor público, é que a seguradora assume uma série de riscos (ex.: trabalhistas, previdenciário, ambiental, entre outros); apesar de serem inseridas cláusulas contratuais que busquem blindar essa responsabilidade, a legislação brasileira não oferece o devido respaldo. Em um comparativo entre legislaçóes, o Palestrante $\mathrm{P}$ indica que a "legislação brasileira não é específica [nem] sobre como uma seguradora pode intervir nos contratos que ela está garantindo". E complementa: "[nos EUA] a legislação tem um processo de sinistro bem estabelecido", não havendo a transferência automática desses riscos para a seguradora.

Existe muita expectativa no mercado segurador brasileiro por conta da nova lei de licitação (Lei n. 14.133, 2021), que pode melhorar o ambiente institucional, oferecendo mais força ao instrumento do SG. Não obstante, questôes importantes deixaram de ser abarcadas: (a) se as seguradoras terão (ou não) liberdade para contratar/substituir o tomador; (b) se haverá (ou não) nova licitação e, em caso positivo, qual o tipo desta (técnica e preço, ou só preço); e (c) qual será a hierarquia entre as partes: direito público ou privado?

Por outro lado, existem aspectos polêmicos no novo marco legal, tais como a penalização da seguradora que não optar pelo step-in, fazendo com que haja incidência de multa no importe de $100 \%$ da verba segurada. Isso pode ser considerado contrário ao princípio indenitário, acarretando longas discussóes e, por conseguinte, insegurança jurídica. Contudo, partindo-se do pressuposto de que o SG possui particularidades frente a outras modalidades de seguro, o princípio indenitário desse instrumento leva em consideraçáo o interesse comum das partes envolvidas, que é o de conclusão de um projeto (performance bond).

O pagamento do valor integral da apólice não tem relação com a perda efetiva. Mas trata-se de uma opção da seguradora caso ela decida por não realizar o step-in. Esse tipo de arranjo pode ser considerado um liquidated damages oriundo da common law, ou danos pré-acordados com a natureza de multa no sistema brasileiro. $\mathrm{O}$ dinheiro pode ser destinado a outros fins que não o projeto garantido. $\mathrm{Ou}$ seja, não existe uma chancela indicando que aquela indenizaçáo terá de ser aplicada no empreendimento segurado. É importante frisar que não há má-fé por parte do poder concedente. Trata-se de um incentivo contratual para a completude do projeto que a seguradora anui ao emitir a apólice. Com isso, dá-se suporte às proposiçóes P5a e P5b.

\section{Regulação}

O SG tem clausulado padrão regido pela circular Susep n. ${ }^{\circ}$ 477/2013 ${ }^{4}$ (Circular, n. 477, de 30 de Setembro, 
2013), em que as disposições contratuais são divididas entre condiçôes gerais, condiçóos especiais e condiçóes particulares. As seguradoras têm a liberdade de alterar apenas esta última parte, desde que náo seja restritivo para o segurado, o que "deixa o produto muito engessado" e, por vezes, "ele não serve para garantir aquele risco específico", explica E8 - em algumas apólices "tudo está definido via condição particular".

Outro aspecto que contribui para a pouca dinamicidade do mercado é a morosidade para se aprovar um novo produto junto à Susep. Ainda que o objetivo da autarquia seja diminuir a AI no mercado, ao padronizar clausulados, não há incentivo à inovação (seja ela genuína, seja importada). Existe ainda certo comodismo por parte das seguradoras quanto ao papel da Susep. O paternalismo estatal acaba gerando o oportunismo e a insegurança jurídica para os mercados, além da evidente ausência de inovação.

É importante notar que a baixa flexibilidade em relação às condiçóes contratuais da apólice acaba gerando oportunismo também por parte do tomador. Porém, nesse tipo de seguro e ainda mais dentro do mercado de infraestrutura, não há que se falar em hipossuficiência. Outro ponto se refere à incompreensão do instrumento, a qual está associada também ao formato dado ao produto pela Susep, cujo objetivo deveria ser fiscalizar o mercado e não "engessar" produtos como ressaltam os entrevistados E7, E8, E10, e como alerta Polido (2015), havendo motivos para identificar sinais de excesso de regulação.

A Susep vem discutindo a obrigatoriedade de vir expresso nas apólices a comissão paga ao corretor. A partir desse dado será possível identificar "se está tendo algum viés" por parte do corretor ou mesmo se "não é só contraprestação [mas] na verdade, comissão", conforme E8. Tal situação é positiva no sentido de auferir transparência ao processo de contrataçáo, produzindo externalidades positivas, objetivo maior de toda regulação.

\section{Insegurança jurídica}

A solução de sinistros nem sempre é feita pelas vias administrativas. Ocorre, porém, que o judiciário brasileiro, de uma maneira geral, conhece pouco sobre seguros e menos ainda sobre SG, não havendo jurisprudência sobre a matéria. Essa falta de previsibilidade em relação ao conteúdo e à aplicação das regras impacta no desenvolvimento da atividade econômica e eleva os custos de transação (Pinheiro, 2014).

Uma discordância ou dúvida sobre os termos do contrato pode levar a intermináveis batalhas judiciais. É uma realidade diferente daquela comentada por todos os entrevistados que trabalham no mercado americano, onde a maior parte dos conflitos é resolvida consensualmente, sem o uso da justiça, mesmo porque o custo da litigância por lá é considerável. Outro ponto comentado por E6 (sobre arbitragem) se refere ao forte posicionamento legal do instrumento nos EUA, o que explica também o refreamento dos americanos em brigar na justiça.

A gama de possibilidades (ou incertezas) no judiciário americano parece relevante, mas elas partem de dispositivos contratuais que são plenamente conhecidos pelos seus atores no âmbito do SG. A insegurança ocorre quando a decisão é repassada para um ente "estranho" na relação, quando não há um consenso entre as partes. No Brasil, seja pelo fato de o mercado ainda náo ser maduro, seja porque o ordenamento jurídico não oferece a liberdade necessária para que os indivíduos transacionem da maneira como eles bem entendam, as discussões são muito mais amplas. Mas não podemos esquecer outro componente: o oportunismo (ou mesmo a má-fé). Sobre esse tema, o Debatedor D amplia a discussão: "a insegurança jurídica está em todos os permeios ... Será que dá mais liberdade de negociar em um claim e tocar a obra para a frente não seria bom? Sem que o CPF dele esteja junto?”

No Brasil, além de não haver uma definição clara e objetiva sobre determinados conceitos, o litígio se torna ainda mais confuso, conforme E4: "você tem um tribunal estatal falando sobre seguro e uma arbitragem ... num contrato de ... uma concessão [ou vice-versa]" - os dois processos correm paralelos e, frequentemente, a seguradora está no judicial, mas não é parte na arbitragem. E5 explica: "seguradora, às vezes, não participa de arbitragens ... [que] têm cláusula de confidencialidade, enfim, uma terceira parte não pode saber o que está acontecendo ali"; e E4 conclui: "Não faz sentido ter uma discussão de seguro num tribunal e a discussão da obrigação garantida em outro".

Toda essa complexa polêmica migra para um judiciário ineficiente, como E3 indicou: "um projeto de infraestrutura não pode esperar 10-15 anos para ser finalizado, por conta de uma brecha para discussão jurídica"; e conclui: "no Brasil, não existe instrumento garantidor que funcione em sua plenitude".

E1 destaca: "é necessário tornar efetivos os instrumentos de recuperação de crédito ... Atualmente, os contratos de contragarantia não são considerados títulos executivos ... fazendo com que a sentença final leve mais de uma década para ser tomada. Nesse meio-tempo, o tomador pode até deixar de existir". Já o Entrevistado E4 comenta: "a seguradora, coitada, fica com aquele CCG ... que náo tem nenhuma liquidez, nenhuma exequibilidade, por isso ela não consegue se ressarcir". O Debatedor D explica que "aqui os sistemas de garantias são superemperrados porque precisa da execução do bem, a venda judicial, esse tipo de coisa. Lá [no exterior] funciona melhor". Um dado importante mencionado por E2 relaciona-se aos "indemnity agreements" (nossos CCGs), os quais "têm força na justiça americana, podendo a decisão final ser obtida em umdois anos no máximo".

A insegurança jurídica no Brasil é ampla e profunda, sendo que toda a sociedade paga um alto custo por ela. $\mathrm{O}$ 
próprio fim social do SG (step-in) não escapa do seu efeito nocivo. Todos os aspectos densamente discutidos nas entrevistas/ dados secundários acima corroboram a literatura (Esplugues \& Marquis, 2015; Pinheiro, 2014). A insegurança jurídica no âmbito do SG no Brasil vai desde uma simples palavra até questóes mais complexas como caducidade e reequilíbrio contratual, passando pela falta de jurisprudência. Os próprios dispositivos contratuais de resoluçáo de disputa se chocam com o procedimento de litígio tradicional. Somam-se ainda a eternidade dos processos, o instrumento de (contra) garantia com efeito mais psicológico do que prático e a ausência de distinções na recuperação de crédito. Por todas essas evidências, e comparativamente em relação à "incerteza" jurídica no mercado americano, conclui-se que existe uma diferença abissal entre os dois países. Portanto, dá-se suporte à proposiçāo $\mathrm{P} 4$.

\section{CONSIDERAÇÕES FINAIS}

Este artigo lança luz sobre questôes típicas do ambiente institucional de países emergentes, como o Brasil, no tocante ao efetivo desenvolvimento de grandes projetos de infraestrutura. As incompletudes, os problemas de agência e os custos de transaçáo presentes na mitigaçáo de riscos de projeto de infraestrutura no Brasil, por meio do instrumento de SG, foram devidamente identificados, compreendidos e avaliados qualitativamente, por meio de entrevistas em profundidade.

Existem questóes que estâo associadas às idiossincrasias constatadas na utilizaçáo do SG no Brasil, como o oportunismo, uma cultura transacional e contratual e a própria mentalidade dos atores envolvidos, que podem levar décadas para serem mudadas. Porém, a raiz do problema pode estar associada ao marco legal existente e à lenta adaptação do mercado segurador a este, condicionada em parte pelas limitaçóes impostas pelo órgão regulador.

O comprometimento menor das seguradoras e o baixo nível de trocas de informaçóes dentro do mercado acarretam subscrição e monitoramento menos eficientes, contribuindo ainda com o despreparo profissional de modo amplo (mesmo dentro do mercado segurador), que alimenta a baixa difusão e o desconhecimento do SG, favorecendo a criação de editais e produtos incongruentes entre si. Pode-se dizer que nesse modelo teórico há um ciclo vicioso.

$\mathrm{O}$ arcabouço legal terminou institucionalizando um mercado de garantias pouco eficazes no setor público, inviabilizando a função social do SG. Essa institucionalização pode ser constatada pelo ambiente de desconfiança que se estabeleceu entre os seus atores, em que a AI e o oportunismo terminam sendo retóricas e causas para a incerteza e externalidades negativas das mais diversas. Nesse aspecto, o judiciário não ajuda, seja pela sua lentidão, seja pela falta de consolidação de jurisprudências nos tribunais superiores ou mesmo pela incompreensão sobre os princípios básicos e condiçóes que norteiam o instrumento.

O presente estudo oferece três principais contribuiçôes acadêmicas para a literatura. Primeiro, amplia o conhecimento sobre mercados e coberturas de riscos em grandes projetos em mercados emergentes como o Brasil. Segundo, diminui as lacunas existentes para o entendimento da utilização do SG como instrumento de mitigação de risco. Terceiro, propóe um modelo conceitual das relaçóes e transaçôes do SG em mercados emergentes como o Brasil. Retomando o modelo conceitual e o analisando à luz das proposiçôes realizadas, bem como dos resultados obtidos, concluímos que ele reflete a realidade dos fenômenos identificados em mercados emergentes como o Brasil. É importante indicar que o objeto da análise está relacionado às transaçóes específicas subjacentes ao uso do SG (aspectos da transaçáo), sendo que os aspectos estruturais surgiram de maneira indutiva durante a pesquisa. As proposiçóes $\mathrm{P} 1, \mathrm{P} 2 \mathrm{a}, \mathrm{P} 2 \mathrm{~b}$ e $\mathrm{P} 4$ se referem à transação em si. Já as proposiçóes P3, P5a e P5b estáo associadas aos aspectos institucionais. Para uma melhor compreensão, indicamos na Figura 3 a seguir o modelo conceitual com ajustes de acordo com os resultados obtidos, bem como a abrangência dos agrupamentos realizados e suas respectivas proposiçôes.

Duas grandes implicaçóes gerenciais podem ser apontadas. A primeira diz respeito à escolha de instrumentos de governança, como assessoria especializada (advisor) ou capacitaçáo de segurados/beneficiários e aprimoramento de standard of procedures, cuja utilização foi parcialmente comprovada nesta pesquisa. A segunda é sobre o desenvolvimento de soluçôes contratuais mais eficazes diante dos fenômenos aqui evidenciados. Com a discriminação de cada um dos efeitos primários e secundários relevantes, é possível pensar no desenvolvimento de instrumentos contratuais (sob a ótica de governos, reguladores, seguradoras, financiadores e do mercado em geral), de forma mais direcionada à mitigação das falhas de mercado subjacentes a cada um desses efeitos. Estabelece aqui, portanto, um 'modelo conceitual' mais efetivo para o desenvolvimento de contratos de mitigação de risco que possam verdadeiramente contribuir para o desenvolvimento dos diversos setores de infraestrutura econômica e social, com grandes implicaçôes sociais e econômicas.

Como limitação do trabalho, buscaram-se na amostra profissionais com pleno conhecimento sobre o SG que estão de algum modo inseridos dentro do mercado segurador. Espera-se que estudos futuros possam ampliar a amostra com representantes do poder concedente, bancos de desenvolvimento, Susep e tomadores dos diferentes setores de infraestrutura, e que novos e importantes achados sejam obtidos. Nota-se ainda que não existe uma base de dados sobre o SG no Brasil que permita a realização de pesquisas mistas (qualitativa e quantitativa) ou mesmo quantitativas. 


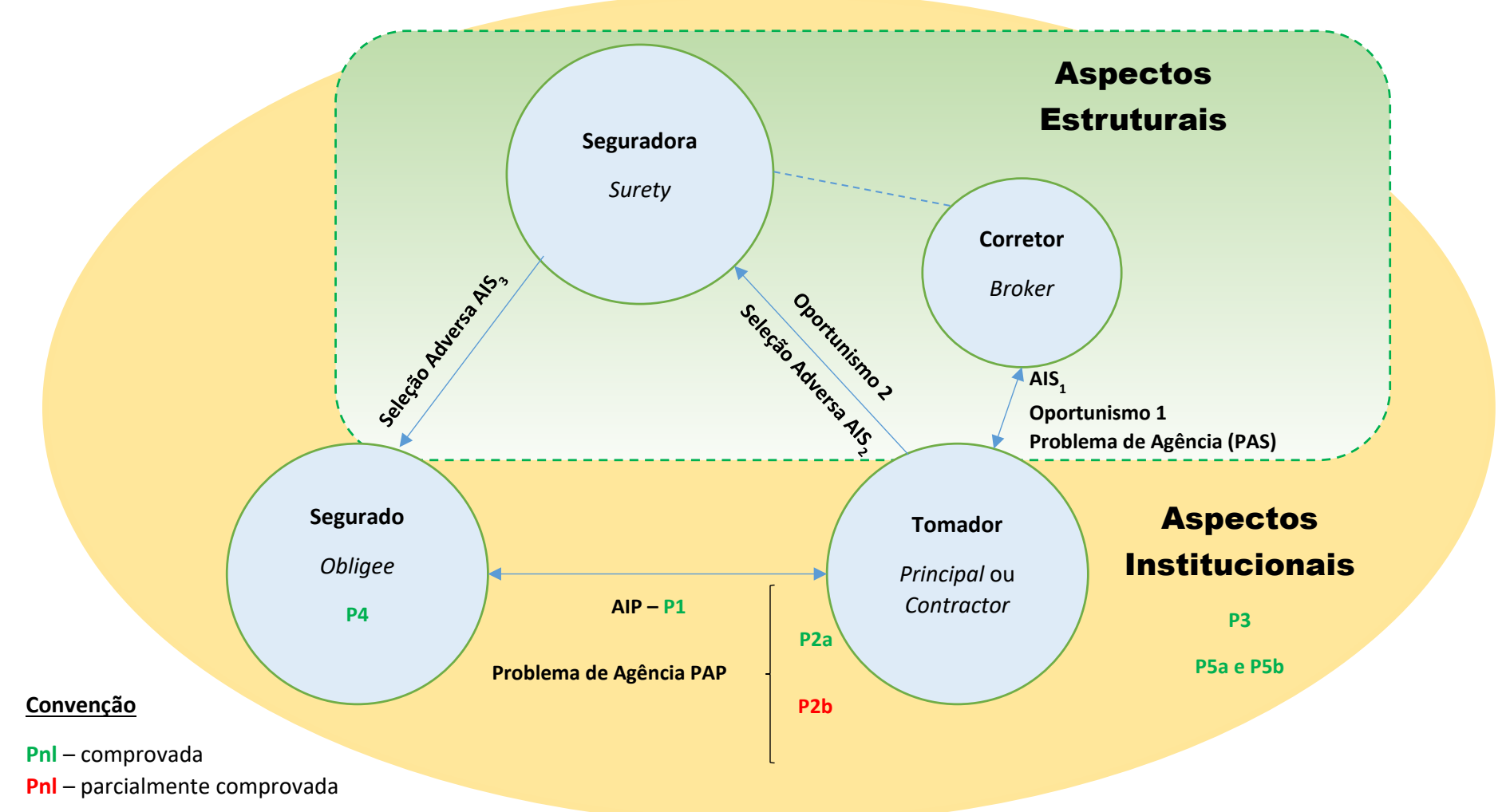

Figura 3. Modelo conceitual final.

Fonte: Elaboração própria.

Este trabalho levantou, em bases qualitativas, a estrutura dos fenômenos subjacentes aos contratos de infraestrutura e ao uso do SG. Como indicação de pesquisa futura, aparece claramente a necessidade de se avançar em direção a uma quantificação do fenômeno. Para uma avaliação mais segura da eficácia do instrumento SG, este estudo propóe um modelo conceitual com indicaçóes analíticas do breakdown do fenômeno. Há dois tipos de efeitos: em primeiro lugar, os efeitos primários, que se referem às questôes básicas de assimetria informacional e problemas de agência inerentes às transaçóes em grandes projetos de infraestrutura, que poderiam ser quantificados em termos das (a) transaçôes evitadas, do (b) custo adicional das transaçôes realizadas em termos de taxas de retorno requeridas pelo risco adicional e outros custos, e ainda das (c) externalidades associadas aos projetos de infraestrutura. Para tornar tangível essa ideia, de forma intuitiva, esses efeitos primários são as consequências negativas das falhas de mercado que ocorrem sem a devida mitigação por instrumentos como o SG.

Em segundo lugar, é importante avançar na quantificação dos efeitos secundários, decorrentes da própria utilização do instrumento do SG como mitigador das falhas primárias. Estes estáo relacionados às questôes de (a) oportunismo contratual, (b) assimetrias informacionais adicionais e (c) problemas de agência, acrescidos ainda de (d) fenômenos semelhantes surgidos na relação peculiar entre corretor e tomador do SG. Essas falhas dão causa não apenas a novos riscos que elevam as taxas de retorno dos projetos (sendo que são elaborados para reduzi-las), mas também à realização indesejada de contratos teratológicos, e à própria sub-realização de projetos de infraestrutura, com as consequentes externalidades positivas que são evitadas. Dessa forma, pode-se dizer que há uma avenida de oportunidade para a agenda de pesquisas futuras, com alto valor social, decorrente deste trabalho, envolvendo a quantificação dos elementos aqui expostos.

\section{NOTAS}

1. É importante registrar aqui a inversão da lógica e nomenclatura apresentada na teoria de agência quando analisamos apenas o contrato firmado entre governo e pepepista (por exemplo), uma vez que o termo principal é utilizado para identificar o contratante na relação.

2. Le Roy e Singell (1987), por exemplo, interpretaram a distinçáo feita por Frank Knight (1921) entre risco e incerteza, como situaçóes em que os mercados de seguros: (a) podem operar sem problemas; e (b) entrariam em colapso devido ao risco moral e à seleção adversa. 
3. As entrevistas foram realizadas em períodos distintos em virtude das fases do desenvolvimento do projeto de pesquisa. Não obstante, a diferença temporal não gerou qualquer impacto na percepçáo dos entrevistados, uma vez que os marcos legal e regulatório, específicos para esta área, permaneceram os mesmos.

4. Em 26/09/2018, a Susep emitiu a Circular n. ${ }^{\circ} 577$ que incluiu no anexo I da circular Susep 477 (de 30/09/2013) o capítulo IV - "Condiçóes Especiais das Coberturas

\section{REFERÊNCIAS}

Akinradewo, O., Aghimien, D., Aigbavboa, C., \& Onyia, M. (2020). Factors influencing the adoption of insurance as a risk treatment tool by contractors in the construction industry. International Journal of Construction Management. https://doi.org/10.1080/15623599.2020.1797986

Arrow, K. J. (1964). Control in large organizations. Management Science, 10(3), 397-408. Retrieved from https://doi.org/10.1287/mnsc.10.3.397

Azevedo, E. M. L., da Silva, A. C. O., \& May, M. R. (2018). Análise do modelo de negócio das ventures builders. Revista de Empreendedorismo e Gestão de Pequenas Empresas, 7(1), 104-129. https://doi.org/10.14211/regepe.v7i1.498

Baker, N.B. (2016). Transaction costs in public-private partnerships: The weight of institutional quality in developing countries revisited. Public Performance \& Management Review, 40(2), 431-455. https://doi.org/10.1080/15309576.2016.1244092

Baker, T., \& Logue, K.D. (2017). Insurance law and policy: Cases and materials. New York, NY: Wolters Kluwer.

Baranoff, E. G., \& Sager, T. W. (2002). The relations among asset risk, product risk, and capital in the life insurance industry. Journal of Banking \& Finance, 26(6), 1181-1197. https://doi.org/10.1016/S0378-4266(01)00166-2

Beg, M. A. (2019). Default insurance and surety bonds: The difference and how they operate. International Journal of Law, 5(1), 30-32.

Bhimani, A., Lopes, A. B., \& Aquino, A. C. B. D. (2016) Measurement costs and control in outsourcing relationships. International Journal of Managerial and Financial Accounting, 8(3-4), 296-318. https://doi.org/10.1504/IJMFA.2016.10002756

Black, B., \& Kraakman, R. (1996). A self-enforcing model of corporate law. Harvard Law Review, 109(8), 1911-1982. https://doi.org/10.2307/1342080

Brockett, P, Golden, L., \& Betak, J. (2019). Different market methods for transferring financial risks in construction. In N. Khatleli (Ed.), Risk management in construction projects. London, UK: IntechOpen.
Adicionais" - ramo 0775. Não obstante, as modificações introduzidas pela circular n. 577 estão circunscritas a contratos de trabalho com dedicação exclusiva de mão de obra, o que, no contexto de projetos de infraestrutura abordados pelo seguro garantia, não têm a menor relevância. É amplamente reconhecido na literatura que os ativos de infraestrutura são capital-intensivos e que o peso do trabalho na função de produção subjacente é de pouca materialidade.
Buranello, R. (2006). Do contrato de seguro: O seguro garantia de obrigaçôes contratuais. São Paulo, SP: Quartier Latin.

Campana, P. (2017). A cultura do medo na administração pública e a ineficiência gerada pelo atual sistema de controle. Revista de Direito, 9(1),189-216. Retrieved from https://periodicos. ufv.br/revistadir/article/view/252703892017090107

Chiles, T. H., \& McMackin, J. F. (1996). Integrating variable risk prefernces, trust, and transaction cost economics. Academy of Management Review, 21(1), 73-99. https://doi.org/10.2307/258630

Circular no 477, de 30 de setembro de 2013. (2013). Dispóe sobre o Seguro Garantia, divulga Condiçôes Padronizadas e dá outras providências. Rio de Janeiro, RJ. Retrieved from https://www.in.gov.br/en/web/dou/-/circular-n-477-de30-de-setembro-de-2013-31065813

Coase, R.H.(1937). Thenatureofthefirm.Economica, 4(16),386-405. https://doi.org/10.1111/j.1468-0335.1937.tb00002.x

Coffee, J. C. (1991). Liquidity versus control: The institutional investor as corporate monitor. Columbia Law Review, 91(6), 1277-1368. https://doi.org/10.2307/1123064

Comer, J. M., Plank, R. E., Reid, D. A., \& Pullins, E. B. (1999). Methods in sales research: Perceived trust in business-tobusiness sales, a new measure. Journal of Personal_Selling \& Sales Management, 19(3), 61-71.

Connelly, B., Crook, T., Combs, J., Ketchen, D. Jr, \& Aguinis, H. (2018). Competence_and integrity-based trust in interorganizational relationships: Which matters more? Journal of Management, 44(3), 919-945. https://doi.org/10.1080/08853134.1999.10754182

Dionne, G. (2013). The empirical measure of information problems with emphasis on insurance fraud and dynamic data. In G. Dionne: Handbook of nsurance (pp.423-448). New York, NY: Springer.

Dumez,_H., \& Jeunemaître, A. (2000). Understanding and regulating the market at a time of globalization: The case of the cement industry. London, UK: Palgrave Macmillan. 
Efing, A. C., \& Desiderio, L. G. M. (2019). A responsabilidade do segurador no seguro garantia de término de obras. Revista de DireitoCivilContemporâneo, 18(6),141-168. Retrievedfrom https://dialnet.unirioja.es/servlet/articulo?codigo $=7611036$

Engel, A., Ganuza, J., Hauk, E., \& Wambach, A. (2006). Managing risky bids. In N. Dimitri, G. Piga., \& G. Spagnolo (Eds.). Handbook of Procurement (pp.322-344). Cambridge, UK: Cambridge University Press.

Esplugues, C., \& Marquis, L. (2015). New developments in civil and commercial mediation. Cham: Springer.

Estache, A., \& Martimort, D. (1999). Politics, transaction costs, and the design of regulatory institutions [World Bank Discussion Paper, 2073]. https://doi.org/10.1596/18139450-2073

Estache, A., Serebrisky, T., \& Wren-Lewis, L. (2015). Financing infrastructure in developing countries. Oxford Review of Economic Policy, 31(3-4), 279-304. Retrieved from https://doi.org/10.1093/oxrep/grv037

Flyvbjerg, B., Garbuio, M., \& Lovallo, D. (2009). Delusion and deception in large infrastructure projects: Two models for_explaining and preventing executive disaster. California Management Review, 51(2), 170-194. https://doi.org/10.2307/41166485

Galiza, F. (2015). Uma análise comparativa do seguro garantia de obras públicas. EstudossobreSeguros, (29),13. Retrieved from https://www.ens.edu.br/arquivos/estudos ed29 fgaliza.pdf

Gentot, M. (1991). Les autorités administratives indépendantes. Paris, FR: Montchrestien.

Giuffrida, L., \& Rovigatti, G. (2019). Supplier selection and contract enforcement: evidence on performance bonding [Discussion Paper 18-045.] Mannheim, GER: Centre for European Economic Research.

Gondim, M. F. Filho, Rosário, J. O. R., \& Freire, L. (2018). Fiscalização do TCU e as garantias constitucionais do processo. Revista Digital Constituição e Garantia de Direitos, 11(2), 155-174. Retrieved from https://periodicos.ufrn. br/constituicaoegarantiadedireitos/article/view/16167

Graham, B., Johnston, N., \& Kingsley, A. (2018). Even constrained government stake: The domestic politics of transfer and expropriation risks. Journal of Conflict Resolution, 62(8), 1784-1813. https://doi.org/10.1177/0022002717701181

Guasch, J.L. (2004). Granting and renegotiating infrastructure concessions: Doing it right. Washington, DC: World Bank.

Guasch, J. L., Laffont, J. J., \& Straub, S. (2008). Renegotiation of concession contracts in Latin America: Evidence from the water and transport sectors. International Journal of Industrial Organization, 26(2), 421-442. https://doi.org/10.1016/j.ijindorg.2007.05.003

Guest, G., Namey, E. E., \& Mitchell, M. L. (2013). Qualitative research: Defining and designing. In Collecting Qualitative Data: A Field Manual for Applied Research (pp.1-40). Thousand Oaks, CA: Sage Publications.
Guimarães, F. (2016). O Direito Administrativo do medo:_A crise da ineficiência pelo controle. Seção Colunistas Direito do Estado. Retrieved from http://www.direitodoestado.com. br/colunistas/fernando-vernalha-guimaraes/o-direitoadministrativo-do-medo-a-crise-da-ineficiencia-pelocontrole

Haddad, M., \& Amaral, C. (2011). O regime jurídico do seguro garantia: Uma análise comparative com o contrato de fiança. In Mattos Filho, Veiga Filho, Marrey Jr, \& Quiroga Advogados (Org.), Construindo um Novo Brasil: Principais desafios do regime jurídico da infraestrutura (pp.69-83). São Paulo, SP: Impressão Régia.

Hansell, D. S. (1996). Introduction to insurance. London, UK: LLP Professional Publishing.

Hart, O., \& Moore, J. (2007). Incomplete contracts and ownership: Some new thoughts. American Economic Review, 97(2), 182-186. https://doi.org/10.1257/aer.97.2.182

Hau, A. (2011). Optimal brokerage commissions for fair insurance: A first order approach. The Geneva Risk and Insurance Review, 36(2), 189-201. https://doi.org/10.1057/grir.2010.11

Hoetker, G., \& Mellewigt, T. (2009). Choice and performance of governance mechanisms: Matching alliance governance to asset type. Strategic Management Journal, 30(10), 10251044. https://doi.org/10.1002/smj.775

Hoffmann, A. F., \& Girolamo, J. A. (2017). O seguro garantia em projetos de infraestrutura. In E. A. R. Contani, \& E. J. R. F. Savóia (Orgs.), Infraestrutura no Brasil: Regulação, Financiamento e Modelagem Contratual. São Paulo, SP: Atlas.

Jensen, M. C., \& Meckling, W. H. (1976). Theory of the firm: Managerial behavior, agency costs and ownership structure. Journal of Financial Economics, 3(4), 305-360. https://doi.org/10.1016/0304-405X(76)90026-X

Kim, H., Cho, H., \& Ryu, D. (2019). Default risk characteristics of construction sure-ty bonds. The Journal of Fixed Income, 29(1), 77-87. https://doi.org/10.3905/jfi.2019.29.1.077

Kim, J., \& Mahoney, J. T. (2005). Property rights theory, transaction costs theory, and agency theory: an organizational economics approach to strategic management. Managerial and Decision Economics, 26(4), 223-242. https://doi.org/10.1002/mde.1218

Krummaker, S. (2016). Corporate demand for insurance: Empirical evidence from Germany [Working_Paper]. City University of London Institutional Repository.

Lakshmi, R.S., \& Santhi, P. (2015). Antecedents of customer perception of service quality of life insurance corporation of India. IUP Journal of Management Research, 14(3), 7081.

Le Roy, S.F., \& Singell, D. (1987). Knight on Risk and Uncertainty. Journal of Political Economy, 95(2), 394-406. https://doi.org/10.1086/261461

Lei $\mathrm{n}^{\circ} 14.133$, de $1^{\circ}$ de abril de 2021. (2021). Lei de Licitaçóes e Contratos Administrativos. Brasília, DF. Retrieved from http://www.planalto.gov.br/ccivil_03/_ato20192022/2021/lei/L14133.htm 
Maher, C., Hadfield, M., Hutchings, M., \& Eyto, A. (2018). Ensuring rigor in qualitative data analysis: A design research approach to coding combining NVivo with traditional material methods. International Journal of Qualitative Methods, 17(1), 1-13. https://doi.org/10.1177\%2F1609406918786362

Maia, F. (2013). A utilização do princípio venire contra factum proprium na isenção de responsabilidade da seguradora em sinistros de seguro garantia. Amazon's Research and Environmental Law, 1(1), 29-51. https://doi.org/10.14690/2317-8442.2013v1199

Mann, R. J. (1998). Verification institutions in financing transactions. Georgetown Law Journal, 87, 2225-2272. https://doi.org/10.2139/ssrn.142669

Marciano, A., Melcarne, A., \& Ramello, G. B. (2019). The economic importance of judi-cial institutions, their performance and the proper way to measure them. Journal of Institutional Economics, 15(1), 81-98. https://doi.org/10.1017/S1744137418000292

Marques, R. C., \& Berg, S. (2011). Risks, contracts, and privatesector participation in infrastructure. JournalofConstruction Engineering and Management, 137(11), 925-932. https://doi.org/10.1061/(ASCE)CO.1943-7862.0000347

Marques, T. H., \& Turolla, F. A. (2017) Há um vazio institucional na mitigação de riscos no setor elétrico brasileiro? $\mathrm{O}$ caso do seguro-garantia. Anais do Seminário de Administração, São Paulo, SP, Brasil, 20.

Monteiro, L.D.S. (2016). As garantias contratuais no âmbito do financiamento de projetos. (Trabalho de Conclusão de Curso de especialização). Insper, São Paulo, SP, Brasil.

Navarro Sanfelix, G., \& Puig, F. (2018). New challenges in franchisor-franchisee relationship. An analysis from agency theory perspective. Cuadernos de Gestión. 18(1), 85-101. https://doi.org/10.5295/cdg.150610gn

Newell, S. J., Wu, B., Leingpibul, D., \& Jiang, Y. (2016). The importance of corporate and salesperson expertise and trust in buildingloyalbusiness-to-business relationshipsin China. Journal of Personal Selling \& Sales Management, 36(2), 160173. https://doi.org/10.1080/08853134.2016.1190656

North, D.C. (1992). Transaction costs, institutions, and economic performance. San Francisco, CA: ICS Press. Retrieved from https://pdf.usaid.gov/pdf docs/PNABM255.pdf

Outreville, J.-F. (2012). The Geneva risk and insurance review 2011: A catalyst for new research ideas. The Geneva Papers on Risk and Insurance, 37(3), 594-602. https://doi.org/10.1057/gpp.2012.30

Panda, B., \& Leepsa, N. M. (2017). Agency theory: Review of theory and evidence on problems and perspectives. Indian Journal of Corporate Governance, 10(1), 74-95. https://doi.org/10.1177\%2F0974686217701467

Pereira, A. N. (2017). Seguro de garantia de obrigaçóes em contratos administrativos: A iniciativa privada e a alternativa pública (Dissertação de mestrado). Universidade Presbiteriana Mackenzie, São Paulo, SP, Brasil.
Pinheiro, A. C. (2014). A justiça e o custo Brasil. Revista USP, 101, 141-158. https://doi.org/10.11606/issn.2316-9036.v0i101p141-158

Poletto, G.A. (2003). O seguro garantia: Em busca de sua natureza jurídica. Rio de Janeiro, RJ: FUNENSEG.

Polido, W. (2015). Regulação do contrato de seguro e reflexos no resseguro: O Brasil abaixo do standard internacional. Anais do Fórum de Direito do Seguro "José Sollero Filho"-IBDS, 6 e Congresso Internacional de Direito do Seguro-Conselho da Justiça Federal e Superior Tribunal de Justiça, 1. São Paulo: Roncarati-IBDS.

Poveda, E. P. R. (2012). Seguro_garantia_como_instrumento de gestáo para a mitigaçâo de danos ambientais na mineração (Tese de doutorado). Universidade Estadual de Campinas, Campinas, SP, Brasil.

Pradhan, R. P., Arvin, M. B., Nair, M., \& Bennett, S. (2020). Unveiling the causal relationships among banking competition, stock and insurance market development, and economic growth in Europe. Structural Change and Economic Dynamics, 55, 74-87. https://doi.org/10.1016/j.strueco.2020.08.006

Reis, V. M. S. (2012). Ensaios sobre seleção adversa e risco moral no mercado de crédito (Dissertação de mestrado). Fundação Getulio Vargas, São Paulo, SP, Brasil.

Ribeiro, J. L. D., Machado, C. O., \& Tinoco, M. A. C. (2010). Determinantes da satisfação e atributos da qualidade em serviços bancários. Gestão \& Produção, 17(4), 775-790. https://doi.org/10.1590/S0104-530X2010000400011

Russell, J. S. (2000). Surety bonds for construction contracts. Reston: ASCE.

Schnaider, P. S. B., Ménard, C., \& Saes, M. S. M. (2018). Heterogeneity of plural forms: A revised transaction cost approach. Managerial and Decision Economics, 39(6), 652663. https://doi.org/10.1002/mde. 2935

Schubert, L. M. (2000). Why obligees buy bonds. In E. G. Gallagher (Ed.), The law of Suretyship. Chicago, IL: ABA.

Shahab,S.,Clinch,J., \&O’Neill,E.(2018).Accountingfortransaction costs in planning policy evaluation. Land Use Policy, 70,263272. https://doi.org/10.1016/j.landusepol.2017.09.028

Silva, E. B. Filho da (2006). A teoria da firma e a abordagem dos custos de transação: elementos para uma crítica institucionalista. Pesquisa \& Debate. Revista do Programa de Estudos Pós-Graduados em Economia Politica, 17(2), 259-277. Retrieved from https://revistas.pucsp.br/index. $\mathrm{php} / \mathrm{rpe} / \mathrm{article} / \mathrm{view} / 11819 / 8544$

Smit, H., Pennings, E., \& Van Bekkum, S. (2017). Real options and institutions. Journal of International Business Studies, 48(5), 620-644. https://doi.org/10.1057/s41267-016-0055-7

Smith, C. W., \& Warner, J. B. (1979). On financial contracting: An analysis of bond covenants. Journal of Financial Economics, 7(2), 117-161. https://doi.org/10.1016/0304-405X(79)90011-4 
Somavilla, J. \& Pereira, A. T. (2018). Possibilidade de utilização da performance bond nos contratos administrativos de obras públicas, à luz da Lei no 8.666/93. Anuário Pesquisa e Extensão Unoesc São Miguel do Oeste, 3, e19788-e19788. Retrieved from https://portalperiodicos.unoesc.edu.br/ apeusmo/article/view/19788

Sun, R.T., Garimella, A., Han, W., Chang, H. L., \& Shaw, M. J. (2020). Transformation of the transaction cost and the agency cost in an organization and the applicability of blockchain: A case study of peer-topeer insurance. Frontiers in Blockchain, 3(24),1-16. https://doi.org/10.3389/fbloc.2020.00024

Superintendência de Seguros Privados (2020a). Registro de operaçóes de seguro garantia passa a ser obrigatório a partir de hoje. Noticias Susep. Retrieved from http://novosite. susep.gov.br/noticias/registro-de-operacoes-de-segurogarantia-passa-a-ser-obrigatorio-a-partir-de-hoje/

Superintendência de Seguros Privados (2020b). Senado aprova projeto de lei de licitaçóes e amplia seguro garantia para obras públicas. Notícias Susep. Retrieved from http:// novosite.susep.gov.br/noticias/senado-aprova-projetode-lei-de-licitacoes-e-amplia-seguro-garantia-para-obraspublicas/

Surahyo, A. (2018). Construction risk analysis and management. In Understanding Construction Contracts (pp.97-106). Cham: Springer

Terra, A. D. M. V., \& Salgado, B. (2020). O risco no seguro garantia e o inadimplemento anterior ao termo. Revista Jurídica Eletrônica da UFPI, 7(1), 18-39. Retrieved from https://revistas.ufpi.br/index.php/raj/article/view/11715

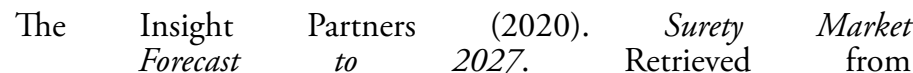
https://www.theinsightpartners.com/reports/surety-market
Tzirulnik, E. (2015). Seguro de riscos de engenharia: Instrumento do desenvolvimento (Tese), Universidade de São Paulo, São Paulo, SP, Brasil.

Wambach, A., \& Engel, A. R. (2011). Surety bonds with fair and unfair pricing. The Geneva Risk and Insurance Review, 36(1), 36-50. https://doi.org/10.1057/grir.2010.8

Williamson, O. E. (2002). The theory of the firm as governance structure: From choice to contract. Journal of Economic Perspectives, 16(3), 171-195. Retrieved from https://www.jstor.org/stable/3216956

Williamson. O. E. (2012). As instituiçôes econômicas do capitalismo: Firmas, mercados e relaçóes contratuais. São Paulo, SP: Pezco Editora.

Yao, J., Zhang, Z., \& Brett, J. (2017). Understanding trust development in negotiations: An interdependent approach. Journal of Organizational Behavior, 38(5), 712729. https://doi.org/10.1002/job.2160

Yescombe, E., \& Farquharson, E. (2018). Public-Private Partnerships for infrastructure: Principles of policy and finance. Oxford: Butterworth-Heinemann.

Yeung,L., Silva,A.L., \& Carvalho, C.E.(2014).Ainsegurançajurídica o devedor: Pela ampliação do debate sobre seleção adversa e custo do crédito no Brasil. Análise Econômica, 32(61), 63-80. https://doi.org/10.22456/2176-5456.33989

Zweifel, P., \& Eisen, R. (2012). Insurance markets and asymmetric information. In Insurance Economics (pp.265-313). Berlin, GER: Springer. 


\section{Autoria}

\section{Tulio Henrique Moreira Marques*}

Escola Superior de Propaganda e Marketing, Programa de Pósgraduaçáo em Administração

Rua Dr. Alvaro Alvim, n. 123, Vila Mariana, 04018-010, São Paulo, SP, Brasil

E-mail: tulio.marqs@gmail.com

(1) https://orcid.org/0000-0003-2656-6072

\section{Mario Henrique Ogasavara}

Escola Superior de Propaganda e Marketing, Programa de Doutorado e Mestrado em Gestão Internacional

Rua Dr. Alvaro Alvim, n. 123, Vila Mariana, 04018-010, Sáo Paulo, SP, Brasil

E-mail: mario.ogasavara@espm.br

(D) https://orcid.org/0000-0001-8988-5762

\section{Frederico Araujo Turolla}

Escola Superior de Propaganda e Marketing, Programa de Doutorado e Mestrado em Gestão Internacional

Rua Dr. Alvaro Alvim, n. 123, Vila Mariana, 04018-010, Sáo

Paulo, SP, Brasil

E-mail: fredturolla2@gmail.com

(1) https://orcid.org/0000-0002-7313-6705

* Autor Correspondente

\section{Financiamento}

Os autores relataram que não houve suporte financeiro para a pesquisa deste artigo.

\section{Conflito de Interesses}

Os autores informaram que não há conflito de interesses.

\section{Verificação de Plágio}

A RAC mantém a prática de submeter todos os documentos aprovados para publicação à verificação de plágio, mediante o emprego de ferramentas específicas, e.g.: iThenticate.

\section{Contribuiç̧ões dos Autores}

$1^{\circ}$ autor: conceituaçáo (liderança); curadoria de dados (igual); análise formal (igual); investigação (igual); metodologia (igual); administraçáo de projeto (igual); recursos (liderança); software (liderança); supervisão (igual); validação (suporte); visualização (suporte); escrita - rascunho original (igual); escrita - revisão e edição (suporte).

$2^{\mathbf{o}}$ autor: conceituação (suporte); curadoria de dados (igual); análise formal (igual); investigação (igual); metodologia (igual); administração de projeto (igual); recursos (suporte); software (suporte); supervisão (igual); validaçáo (liderança); visualização (liderança); escrita - rascunho original (igual); escrita - revisão e edição (liderança).

$3^{\mathbf{o}}$ autor: conceituação (suporte); curadoria de dados (igual); análise formal (igual); investigação (igual); metodologia (igual); administração de projeto (igual); recursos (suporte); software (suporte); supervisão (igual); validação (suporte); visualização (liderança); escrita - rascunho original (igual); escrita - revisão e edição (liderança).

\section{Direitos Autorais}

A RAC detém os direitos autorais deste conteúdo.

\section{Método de Revisão por Pares}

Este conteúdo foi avaliado utilizando o processo de revisão por pares duplo-cego (double-blind peer-review). A divulgação das informaçóes dos pareceristas constantes na primeira página e do Relatório de Revisão por Pares (Peer Review Report) é feita somente após a conclusão do processo avaliativo, e com o consentimento voluntário dos respectivos pareceristas e autores.

\section{Disponibilidade dos Dados}

A RAC incentiva o compartilhamento de dados mas, por observância a ditames éticos, não demanda a divulgaçáo de qualquer meio de identificação de sujeitos de pesquisa, preservando a privacidade dos sujeitos de pesquisa. A prática de open data é viabilizar a reproducibilidade de resultados, e assegurar a irrestrita transparência dos resultados da pesquisa publicada, sem que seja demandada a identidade de sujeitos de pesquisa. 